\title{
INSCRIPCIONES ÁRABES INÉDITAS EN EL MUSEO PROVINCIAL DE ALMERÍA ${ }^{1}$
}

Jorge LiROLA DELGADO
Universidad de Almería

Almería, en su época árabo-islámica, produjo un gran número de inscripciones que destacan no sólo por su cantidad, sino también por su calidad, talladas casi la totalidad de ellas, con gran suntuosidad, en mármol blanco procedente de las canteras de Macael (Sierra de los Filabres).

En el año 1964 apareció publicada la excelente obra Repertorio de inscripciones árabes de Almería, de Manuel Ocaña Jiménez, tras un prolongado retraso, pues la impresión del libro comenzó a finales de $1950^{2}$. En esta obra el insigne epigrafista recopiló todas las inscripciones árabes de Almería que conocía y que se encontraban repartidas en diversas colecciones, según puede comprobarse en el cuadro . $^{\circ} 1$. Su labor no se limitó a reunir y revisar las numerosas inscripciones que ya habían sido estudiadas, fundamentalmente, por R. Amador de los Ríos (en 1876 y 1883), R. Revilla Vielva (en 1924, 1932 y 1935), E. Lévi-Provençal (en 1931) y W. Caskel (en 1936), enmendando no pocos errores u ofreciendo lectura allí donde otros no habían podido realizarla, sino que añadía una treintena de inscripciones inéditas, hasta formar un corpus de 118 inscripciones (113 de la ciudad de Almería y 5 de la provincia).

\footnotetext{
${ }^{1}$ Quiero dejar constancia de mi gratitud a la Delegación Provincial de Cultura de Almería y a la Dirección General de Instituciones del Patrimonio Histórico de la Junta de Andalucía, por la rapidez con la que fue tramitada la autorización que me ha permitido acceder a los fondos del Museo, y a todo el personal de este último, por las facilidades que me han ofrecido y su amabilidad, en particular a su Conservador, D. Miguel Ángel Fernández López, por su disponibilidad y presteza, y a su Director, D. Ángel Pérez Casas. Asimismo, quiero agradecer a Isabel Flores Escobosa su colaboración en la resolución de las dudas que le he planteado, así como el hecho de que haya servido, en cierto modo, de motor para que adelante el proyecto del estudio de las inscripciones árabes de Almería; e igualmente a Rachid El Hour, por sus sugerencias para mejorar algunas de las lecturas que había realizado de las inscripciones.

${ }^{2}$ Así lo explica el propio autor en su trabajo «Historia y epigrafía en la Almería islámica», Homenaje al Padre Tapia. Almería en la Historia, Almería, 1988, 174. La razón que ofrece como explicación de la larga demora es el hecho de que hubiese recogido con nombres y apellidos cómo gran parte de las inscripciones fueron transferidas al extranjero.
} 


\begin{tabular}{|lcc|}
\hline \multicolumn{1}{|c}{ Colección } & N. $^{\mathbf{0}}$ inscrip. & \% \\
\hline The Hispanic Society of America (Nueva York) & $47+4{ }^{1 / 2}$ & 41,53 \\
\hline Museo de la Alcazaba de Almería & $21+1^{1 / 2}$ & 18,22 \\
\hline Instituto de Valencia de Don Juan (Madrid) & $20+1^{1 / 1} / 2$ & 17,37 \\
\hline Museo Arqueológico Nacional (Madrid) & $11+3^{1 / 2}$ & 10,59 \\
\hline Museo Arqueológico de la Alhambra (Granada) & $5+1 \frac{1}{1 / 2}$ & 4,66 \\
\hline Martínez de Castro (Almería) & 5 & 4,24 \\
\hline Museo de la Alcazaba de Málaga & 3 & 2,54 \\
\hline Perdidas & 1 & 0,85 \\
\hline Total & $113+10^{1 / 2}$ & 100,00 \\
\hline
\end{tabular}

Cuadro.$^{\circ}$ 1: Distribución por colecciones de las inscripciones estudiadas por Ocaña.

Con el signo $1 / 2$ se señala el fragmento que, junto a otro de otra colección, forma parte de una misma inscripción. En total son 5 los casos en los que esta circunstancia se produce.

La obra de Ocaña pronto se convirtió en todo un hito dentro de los estudios de epigrafía andalusí, siendo referencia casi obligada, pues al interés del preciso y docto trabajo del autor había que sumar el elevado número de inscripciones que se conservaban de la ciudad que había sido, desde mediados del siglo $\mathrm{x}$ hasta mediados del XII, uno de los principales puertos no sólo de al-Andalus, sino de todo el Mediterráneo. Almería es, sin duda, la ciudad andalusí que tuvo la más rica colección de inscripciones.

Aunque en el Repertorio pueden encontrarse piezas de todos los grandes períodos históricos de al-Andalus, la mayoría de las inscripciones, en concreto el 72 por 100, data de la época almorávide, cuando la ciudad de Almería era «la ciudad del Islam», en palabras de al-Idrīsī, quien destaca que «en ella había toda clase de industrias maravillosas ... y a ella se dirigian los barcos mercantes procedentes de Alejandría y Siria; no había en todo al-Andalus gente más adinerada que los almerienses, ni más inclinada a toda clase de comercios que ellos, vendiendo y atesorando ${ }^{3}$. El mismo geógrafo ceutí subraya que

\footnotetext{
${ }^{3}$ Al-Idrīsī, Nuzhat al-muštāq, Beirut, 2 vols., 1989 (= ed. E. Cerulli, F. Gabrieli, G. Levi Della Vida y otros, Opus Geographicum, 9 fascículos, Nápoles, 1970-75), vol. II, 562.
} 
esta ciudad tenía «una abundante actividad comercial; los viajeros que afluían a ella eran cuantiosos y sus habitantes vivian holgadamente, sin que hubiera en al-Andalus gentes más acaudaladas ni con más desahogo que ellos» ${ }^{4}$.

De las inscripciones estudiadas por Ocaña, la más antigua procede de Pechina y data del 239/854, a la que le sigue, ya propiamente de Almería, una del 312/924. La más tardía data del 798/1395 ${ }^{5}$.

\begin{tabular}{|c|c|c|}
\hline Época & N..$^{\circ}$ inscrip. & $\%$ \\
\hline Emirato & $3 / 2$ & $2,54 / 1,69$ \\
\hline Califato & $9 / 10$ & $7,63 / 8,47$ \\
\hline Taifas & 12 & 10,17 \\
\hline Almorávides & 85 & 72,03 \\
\hline Almohades & 6 & 5,09 \\
\hline Nazaríes & 3 & 2,54 \\
\hline Total & 118 & 100,00 \\
\hline
\end{tabular}

Cuadro n..$^{\circ}$ 2: Distribución por épocas de las inscripciones estudiadas por Ocaña.

Si analizamos el carácter de las inscripciones, destaca el elevado número de estelas funerarias, según puede comprobarse en el cuadro n..$^{\circ}$, procediendo, por tanto, de alguno de los cementerios islámicos de la ciudad. Sin duda, la riqueza de parte de los habitantes de Almería durante la época almorávide, a la que se refería al-Idrīsī, explica ese elevado número de suntuosas inscripciones funerarias.

\begin{tabular}{|lrr|}
\hline \multicolumn{1}{c}{ Carácter } & N. $^{\mathbf{0}}$ & \multicolumn{1}{c|}{$\%$} \\
\hline Epitafios & 112 & 94,90 \\
\hline Fundacionales y conmemorativas & 5 & 4,25 \\
\hline Sin determinar & 1 & 0,85 \\
\hline Total & 118 & 100,00 \\
\hline
\end{tabular}

Cuadro n. ${ }^{\circ}$ : Carácter de las inscripciones estudiadas por Ocaña.

${ }^{4}$ Al-Idrīsī, Nuzha, II, 563.

${ }^{5} \mathrm{Se}$ trata de las inscripciones $n .^{\circ} 114,1$ y 112 , respectivamente. 
En la «advertencia» inicial a su Repertorio, Ocaña anunciaba que posponía para otro momento, por razones de tiempo, el estudio detallado de la evolución de la escritura cúfica de Almería; el método del que se había valido para fechar de forma muy precisa las inscripciones carentes de data expresa, que eran más de la mitad; y un análisis de los diferentes tipos de inscripciones y de las clases de monumentos funerarios ${ }^{6}$. Años más tarde, en el trabajo que publicó bajo el título de «Historia y epigrafía en la Almería islámica» ${ }^{7}$ trató de cumplir con lo prometido, aunque, seguramente de nuevo por falta de tiempo, lo hizo en algunos puntos sin la profundidad y la exhaustividad que hubiera sido de desear, máxime si tenemos en cuenta que era la persona más capacitada para ello.

Dado que me proponía retomar el tema del estudio de las inscripciones árabes de Almería, en particular la evolución del cúfico en esta ciudad, comencé por examinar aquellas inscripciones que me resultaban más accesibles, las que se conservaban en la misma ciudad. Las mencionadas por Ocaña en su Repertorio como pertenecientes a los fondos del Museo de la Alcazaba de Almería se encuentran en la actualidad repartidas entre el Museo Provincial y la Alcazaba. En concreto, en el primero se hallan las inscripciones n. ${ }^{\circ} 9,18,22$ (únicamente el fragmento con epigrafía, el más grande), 24, 35, 40, 52 (sólo un fragmento, el más grande), 53, 55, 69, 84, 100, 102, 104, 110 y 112; mientras que en la Alcazaba de Almería se encuentran las n. ${ }^{\circ} 41,77,88$ (la parte correspondiente), 93 y 96 . El resto, es decir, los dos fragmentos pequeños de la $n^{\circ} 22$, el fragmento pequeño de la n. $^{\circ} 52$, y la.$^{\circ} 62$ no he conseguido localizarlas en ninguno de los dos centros visitados.

Las que Ocaña consultó en la Colección de Martínez de Castro se encuentran ahora en el Museo Provincial de Almería, salvo la número 85, que no he podido hallar; se trata de $\operatorname{los} \mathrm{n}^{.}{ }^{\text {s }} 3,5,13$ y 67 de su Repertorio.

Aparte de esas inscripciones, tanto en el Museo Provincial como en la Alcazaba, existe un buen número de inscripciones inéditas que no aparecen, por tanto, en el Repertorio de Ocaña y que han pasado desapercibidas hasta la fecha. Dado su elevado número, voy a ocuparme en este trabajo únicamente de las del Museo, dejando para un próximo trabajo las de la Alcazaba ${ }^{8}$.

En el caso del Museo se trata de 25 fragmentos inéditos, con inscripción, además de otros, sólo con motivos decorativos. Forman parte de 19 inscripciones. La mayoría de ellas, trece, son de carácter funerario, como cabía esperar; dos son fundacionales, ya conocidas; y el resto, cuatro, son decorativas.

${ }^{6}$ Ocaña, M., Repertorio de inscripciones árabes de Almería, Madrid-Granada, 1964, IX.

${ }^{7}$ Homenaje al Padre Tapia. Almería en la Historia, Almería, 1988, 173-188.

${ }^{8}$ En este último caso, son 20 fragmentos pertenecientes a 14 inscripciones. 
El Museo, que llevó hasta 1981 el nombre de Luis Siret en homenaje al ilustre arqueólogo belga que impulsó los estudios arqueológicos en la provincia de Almería, se encuentra cerrado al público desde 1991, como consecuencia del mal estado en el que se halla el edificio. Mientras que las autoridades competentes se decidían a dar una solución al problema, se habilitaron, en otros puntos de la ciudad, dos exposiciones para piezas de la prehistoria y la historia antigua de Almería, no así para el período medieval, por lo que ninguna de las piezas aquí estudiadas ha estado expuesta en los últimos años ni lo está en la actualidad. Salvo las n. 2 y 12 , que estaban expuestas en la sala correspondiente del Museo, el resto se encuentra en diferentes almacenes. Una de ellas, la n..$^{\circ}$, fue mostrada en la Exposición sobre Cultura Islámica en España (Toledo, 1987) y la Expo'92 (Sevilla, 1992). Las n. 2 y 12, ambas de carácter fundacional, habían sido recogidas por Ocaña, aunque dado que, desde que éste se ocupó de ellas, han aparecido nuevos fragmentos y se pueden dar nuevos datos sobre las mismas, las incluyo en este trabajo.

Todas las inscripciones estudiadas aquí ingresaron en el Museo en 1981, cuando se trasladó la sede del mismo al edificio actual. Todas ellas procedían de la Alcazaba, donde habían estado depositadas desde fecha indeterminada y sin que se conozca realmente de dónde proceden, salvo dos casos, en concreto la $\mathrm{n}^{\circ}$ 13 (calle Trajano) y n. ${ }^{\circ} 18$ (calle Javier Sanz). Ello es debido a que no se conserva en la Alcazaba ningún registro de esa época que pudiera arrojar luz al respecto. Es probable que algunas procedan de la misma Alcazaba. Éste debe de ser el caso de la n..$^{\circ} 12$, dado que el resto de los fragmentos de esa inscripción aparecieron en el interior del segundo recinto, al pie de la muralla meridional, durante la campaña de exploraciones del año $1943^{9}$. No obstante, la mayoría procedería de alguno de los antiguos cementerios de la ciudad. Creo que no habría que descartar que algunas de estas inscripciones, junto con otras de las inéditas de la Alcazaba, puedan formar parte de la veintena que fueron halladas en torno al año 1960 cerca de la calle Granada, es decir, en el recinto que ocupaba el Cementerio de la Puerta de Pechina (Maqbarat Bāb Baŷȳāna) ${ }^{10}$.

Algunas de las inéditas debieron de formar parte de la colección de Juan Antonio Martínez de Castro, pues, según precisó Juan Cuadrado Ruiz, director entonces del Museo, al recoger la noticia de su adquisición poco antes de 1949, la colección estaba «compuesta de ocho lápidas epigráficas árabes, incomple-

\footnotetext{
${ }^{9}$ Así lo precisa Ocaña, Repertorio, 98.

${ }^{10}$ De ese hallazgo dio cuenta M. ${ }^{a}$ A. Martínez Núñez, al estudiar una de esas inscripciones, que llegó a manos de un malagueño, en «Inscripción sepulcral almeriense descubierta en Málaga», Jábega, 24 (1978), 13-15.
} 
tas, en mármol» ${ }^{11}$ y no sólo las cinco (o seis, si se considera la n. ${ }^{\circ} 13$ como dos fragmentos) a las que se refirió Ocaña en su Repertorio.

El resto de las piezas también aparecieron antes de que se publicase la obra de Ocaña en 1964. Sin embargo, en la advertencia preliminar de la misma, señala que «no se ha producido en todo este tiempo ningún descubrimiento que haya de añadirse a este Repertorio». Tampoco tuvo conocimiento de las mismas con posterioridad, pues en el trabajo que compuso en 1986, en el que volvía sobre las inscripciones de Almería con motivo del Homenaje al Padre Tapia, nada dice al respecto, salvo el hecho de llamar la atención sobre la aparición del fragmento de la inscripción fundacional del 955 del que había tenido conocimento a raíz de un dibujo que encontró en el Instituto de Valencia de Don Juan. Ese nuevo fragmento pudo verlo al estar expuesto en el Museo Arqueológico, cuando lo visitó durante aquella estancia en Almería ${ }^{12}$.

Fernando Ochotorena, allá por los años sesenta, instaló en los aljibes califales del segundo recinto de la Alcazaba una especie de museo en el que estuvieron muchas de las piezas aquí estudiadas, quedando ahora en ellas restos de escayola, además de pintura de color ocre, por su parte trasera ${ }^{13}$.

El orden elegido para presentar las inscripciones en este trabajo es el cronológico, disponiéndolas desde la más antigua a la más tardía. Tan sólo dos de las 19 llevan mención expresa de la fecha, por lo que en el resto es preciso deducirla. El procedimiento utilizado ha sido el habitual en estos casos: atender a los rasgos epigráficos, el contenido textual, la forma y los motivos decorativos utilizados. El marco cronológico se extiende desde el segundo cuarto del siglo $\mathrm{X}$ al siglo XII, predominando claramente las piezas de la época almorávide, en consonancia con los datos que se ofrecían anteriormente. Las dos con fecha expresa son de la primera mitad del siglo XII, en concreto del 510/1116 (n..$\left.^{\circ}\right)$ y $528 / 1134\left(\right.$ n. $\left.^{\circ} 11\right)$.

En cuanto a la técnica de labra utilizada, todas las inscripciones fueron realizadas en resalte. El material utilizado fue el mármol blanco de Macael, salvo en la n. ${ }^{\circ} 19$, en la que se utilizó un mármol de color rosáceo.

El análisis pormenorizado de los rasgos epigráficos de las inscripciones lo dejo para un estudio conjunto que estoy preparando de todas las inscripciones

\footnotetext{
${ }^{11}$ Cuadrado Ruiz, J., Una visita al Museo Arqueológico Provincial de Almería, Almería, 1949, 87.

12 Ocaña, «Historia y epigrafía», 176.

${ }^{13}$ En Cara Barrionuevo, L., La Almería islámica y su Alcazaba, Almería, 1990, 234, aparece una fotografía en la que quedan aún restos de ese museo antés de ser desmantelado. Entre esos restos son visibles los agujeros que quedaron en la pared tras extraer las inscripciones, que habían estado adheridas a ella con escayola.
} 
árabes de Almería, incluidas las que fueron estudiadas por Ocaña. Tras dicho estudio, probablemente, podré ser más preciso en la cronología e incluso puede que sea necesario corregir algunas de las propuestas hechas ahora. Dejo, asimismo, para la referida obra la reconstrucción de algunos de los fragmentos perdidos. Únicamente ofrezco, como botón de muestra, la reconstrucción de una de ellas, la n. ${ }^{\circ} 8$, a la que le faltaba tan sólo un pequeño fragmento fácilmente reconstruible por uno de sus frentes, el posterior.

En la ficha de cada pieza he seguido, en parte, el criterio adoptado por Carmen Barceló en su excelente estudio de las inscripciones valencianas ${ }^{14}$. En los datos que ofrezco de las dimensiones de las piezas, la letra $A$ se refiere a la altura, la $L$ a la latitud o anchura y la $G$ al grosor. Todas las medidas se dan en centímetros, dado que sólo en contadas ocasiones algunas de las magnitudes de las inscripciones superan el metro.

En lugar de las fotografías correspondientes, he preferido ofrecer los dibujos de las inscripciones dado que éstos pueden ayudar más a observar los trazos de las letras.

Las citas coránicas las doy a través de la traducción de J. Cortés, aunque en algunos casos me he visto obligado a modificar el orden de la traducción para marcar las partes conservadas.

Aparte del valor en sí de las piezas, el interés de las mismas radica en que con ellas se amplía el corpus de inscripciones conocidas, lo que permitirá tener más datos para el estudio de la tipología de los enterramientos, la evolución del cúfico, el trabajo de los tallistas y la categoría socio-económica de los difuntos.

Para terminar, es preciso advertir que no he recogido las inscripciones en cerámica, de las que hay algunas muestras en el Museo.

Fecha: [Segundo cuarto del siglo $\mathrm{x}$ ].

Definición: Epitafio.

Procedencia: Desconocida.

Ubicación: Museo Provincial de Almería. N. ${ }^{\circ}$ de inventario: 23.557.

Materia: Mármol blanco.

Forma: Probablemente rectangular alargada.

Medidas: A $38 \mathrm{~cm}$ x L $40 \mathrm{~cm}$ x G $5 \mathrm{~cm}$.

${ }^{14}$ Barceló, C., La escritura árabe en el País Valenciano. Inscripciones monumentales, 2 vols., Valencia, 1998, I, 123-124. 

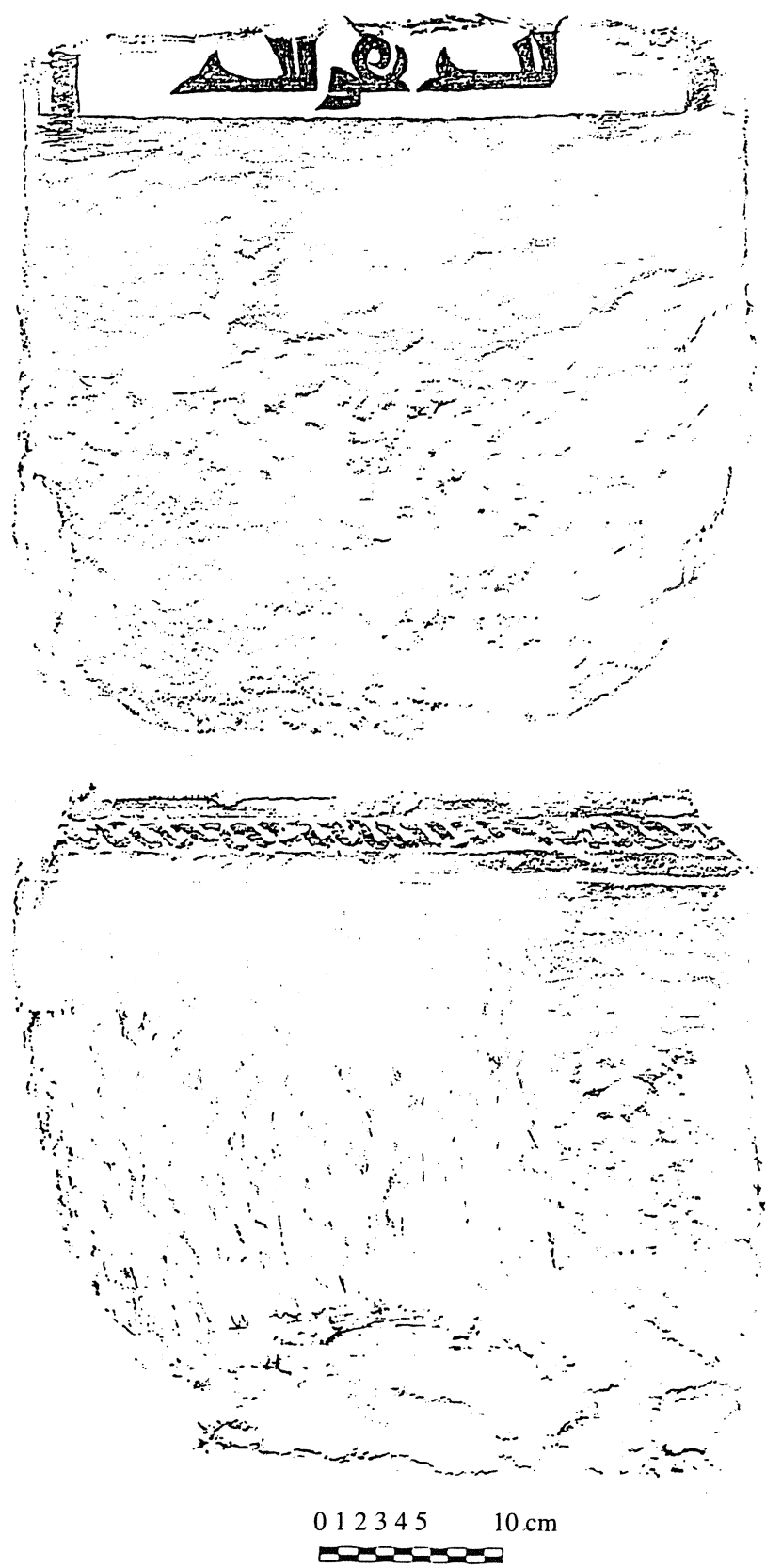

N. ${ }^{\circ} 1$ (Segundo cuarto del siglo $\mathrm{x}$ ). Anverso y reverso. 
Número de líneas: 1 .

Tipo de letra: Cúfico florido.

Conservación: Fragmento de la parte inferior, con restos de la faja de enmarque en ambos laterales por una cara y con adorno de cenefa trenzada de doble cinta por la otra. Deteriorada.

Bibliografía: Inédita.

Texto:

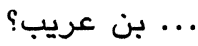

Traducción:

... Ibn ${ }^{\mathrm{c} A r i b /}{ }^{\mathrm{C}}$ Urayb (?)

\section{Comentario:}

Se trata claramente de una losa sepulcral, pues la parte inferior, que se hincaba en la tierra, no está pulida ni tallada.

Resulta significativo el hecho de que aparezca labrada por ambas caras, al igual que otras cinco almerienses estudiadas por Ocaña, las n. ${ }^{\circ} 1$ (año 312/924), 2 (año 320/932), 3 (primer tercio del siglo IV), 4 (año 345/956) y 29 (año 507/1113).

La forma de la ${ }^{c}$ ayn es idéntica a la que aparece en una de esas inscripciones, en concreto la fechada en el 320/932 (Ocaña, Repertorio, n. ${ }^{\circ}$ 2).

No estoy seguro de haber realizado una lectura correcta, en particular del primer elemento ( $\mathrm{lbn}$ ), no tanto por el hecho de que no aparezca el alif inicial, pese a ser principio de línea - omisión que se producía con frecuencia-, como por el trazo final de esa primera palabra, que quizá no haya que considerar una figura 14f (nūn final), sino una $2 \mathrm{f}$ (grupo $b \bar{a}^{\prime}, t \bar{a}^{\prime}$ y $t \bar{a}$ ' final), dado que la $n \bar{u} n$ final suele tener o un trazo descente y/o ascendente. En este último caso habría que considerar la posibilidad de que fuese el final de una palabra que habría comenzado en la línea anterior y que, por tanto, habría sido cortada, lo cual era una práctica habitual.

Fecha: $\mathrm{rabi}^{\mathrm{c}}$ II $34[$ ¿4?] = ¿25 julio-22 agosto 95[5]?

Definición: Inscripción fundacional a nombre del califa omeya 'Abd alRaḥmān III y el qā'id 'Abd al-Raḥmān b. Rumāhịis. 
Procedencia: Desconocida. Perteneció a la Colección Martínez de Castro, de la que pasó a la Alcazaba y de allí al actual Museo Provincial de Almería. Había pertenecido previamente a Juan de Mata García.

Ubicación: Museo Provincial de Almería. N. ${ }^{\circ}$ de inventario: 23.552.

Materia: Mármol blanco.

Forma: Rectangular levemente alargada o quizá casi cuadrada.

Medidas: A $78 \mathrm{~cm} \mathrm{x} \mathrm{L} 44 \mathrm{~cm}$ x G $7 \mathrm{~cm}$.

Número de líneas: 8 , incompletas todas ellas.

Tipo de letra: Cúfico florido.

Conservación: Muy deteriorada y desgastada, afectando enormemente a la escritura. La gran erosión sufrida ha podido estar motivada por haber estado expuesta largo tiempo a las inclemencias meteorológicas. En la actualidad está constituida por dos fragmentos unidos. Cuando pertenecía a Juan de Mata García, los dos fragmentos formaban uno solo, como lo acredita el dibujo que realizó de la misma Nicanor Peralta y que se conserva en el Instituto Valencia de Don Juan. Al fragmentarse se perdió un pequeño trozo en su costado izquierdo.

Bibliografía: OCAÑA, Repertorio, n. ${ }^{\circ}$ 5, pp. 4-5, n. ${ }^{\circ} 5$ y lámina III, a (fragmento inferior); OCAÑA, El cúfico hispano y su evolución, Madrid, 1970, pp. 3233 y lámina XV (fragmento inferior y dibujo de Nicanor Peralta); y OCAÑA, «Historia», pp. 175-176 y 178.

Texto:

$$
\begin{aligned}
& 1
\end{aligned}
$$

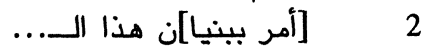

$$
\begin{aligned}
& 3 \\
& \text {..... } 4 \\
& 5 \\
& 6
\end{aligned}
$$

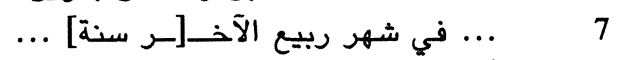

$$
\begin{aligned}
& 8
\end{aligned}
$$

\section{Traducción:}

|[En el nombre de Dios, Clemen]te [y Misericordioso,] ... İ[mandó cons-

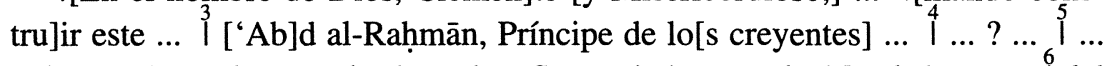
[Dios] — - ihonrado y ensalzado sea!- - Se terminó y completó [... de la mano i del ca]íd Muhammad ibn Rumāhis con la ayu[da de Dios] ... I ... en el mes de $r a b{ }^{c}$ el postrero ... [del año] ... I cuarenta y tres[cientos]. 


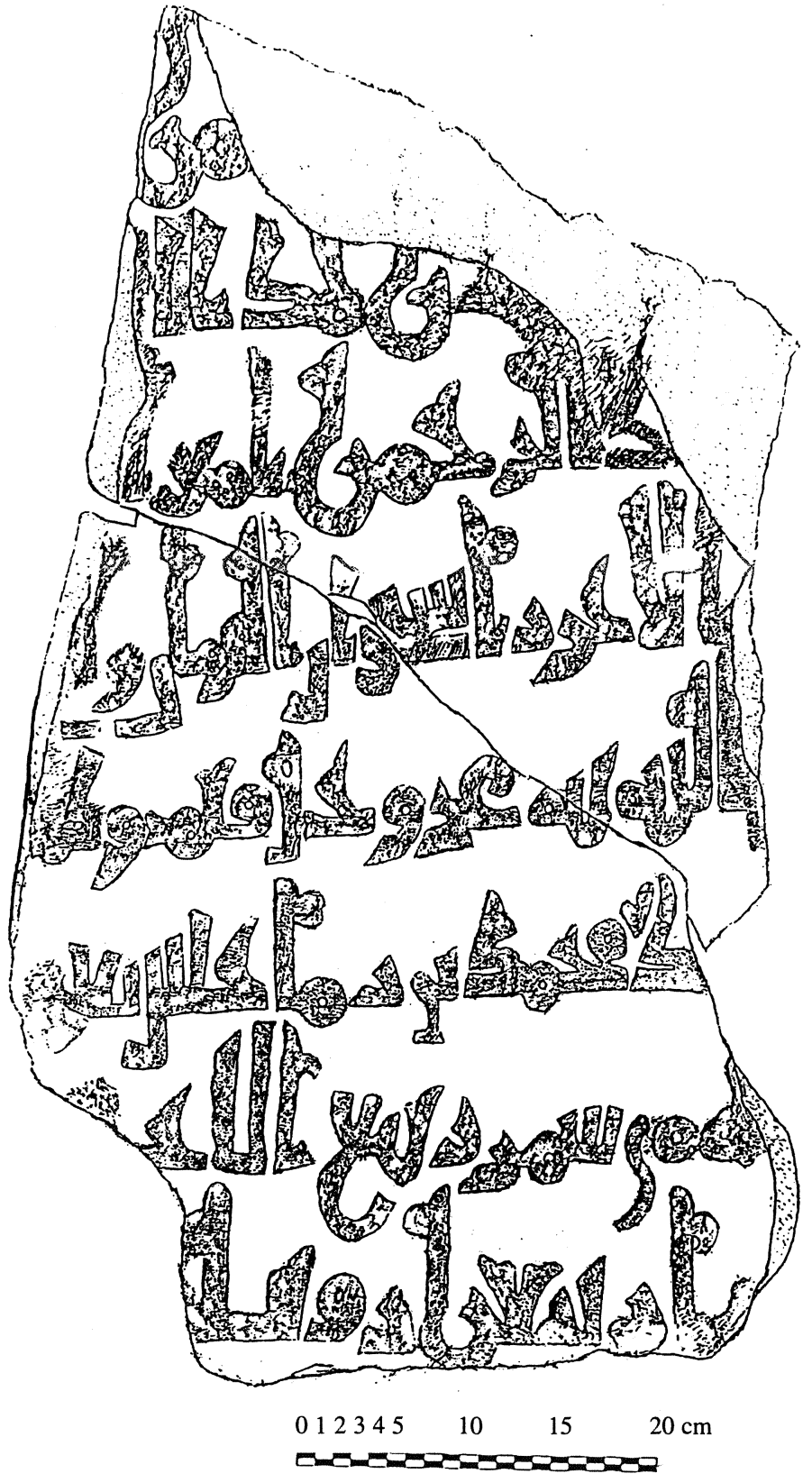

N..$^{\circ}(¿ 344 / 955 ?)$ 


\section{Comentario:}

Ocaña, al hacer una primera lectura del dibujo y del fragmento inferior, señaló que conmemoraría alguna de las obras que debieron hacerse en Almería con motivo de la fundación de la ciudad en época de 'Abd al-Raḥmān III ${ }^{15}$. Años más tarde, tras poder leer el nombre completo del $q \bar{a}$ ' $i d$ Muhammad ibn Rumāhis, propuso que quizá no se refiriera al amurallamiento de la ciudad, que al-Ḥimyarī fecha en el año 344/955-56, sino a «la construcción de algún arsenal, pues en su quinta línea [aquí sexta], concretamente, parece seguro que está consignado el nombre del $q \bar{a}$ 'id Muhammad b. Rumāhis, lo que induce a aseverar —según él- que las obras conmemoradas en ella eran de carácter marítimo, ya que todos los Banū Rumāhis, sin excepción, fueron renombrados hombres de mar en los días del Califato» ${ }^{16}$.

Bien es cierto que al-Rušātị menciona expresamente que 'Abd al-Rahmān III construyó las atarazanas de Almería en el año 344/955-56, tras el ataque fatimí que destruyó la ciudad y que fechó el martes $8 \mathrm{rabi}^{\mathrm{c}}$ I $344 / 3$ julio $955^{17}$, pero creo que no hay que descartar que la inscripción conmemorase la construcción de la cerca de la ciudad, pues, por un lado, gracias a al-'Udrī sabemos que los Banū Rumāḥis no sólo fueron almirantes de la flota, sino que también ocuparon el cargo de gobernador de la cora; de ahí que la mención de Muḥammad ibn Rumāhis no sea, necesariamente, indicio del carácter marítimo de la obra. Por otro lado, hemos de tener en cuenta que en este tipo de inscripciones suele aparecer especificado el carácter de la obra. Así ocurre, por ejemplo, en la que conmemora la construcción de las atarazanas de Tortosa en $333 / 944{ }^{18}$ o las de la Rábita de Guardamar ${ }^{19}$. A este respecto, el término utilizado para atarazanas, $d \bar{a} r a l-\sin \bar{a} c a$, es femenino, mientras que tanto el demostrativo hă $\underline{\text { a }}$ como el verbo tamma, utilizados en relación con la obra cuya construcción se conmemora, tienen forma masculina. Esto me hace pensar que habría de tratarse de otro tipo de obra, que bien podría ser la construcción de la muralla $(s \bar{u} r)$, masculino en árabe.

El año 344/955 no es seguro, pues, si analizamos las fuentes árabes que conocemos, observaremos que presenta problemas. Si tenemos en cuenta la fecha ya mencionada en la que, según al-Rušătīin, se produjo el ataque fatimí a

\footnotetext{
${ }^{15}$ Ocaña, Repertorio, 5.

${ }^{16}$ Ocaña, M., El cúfico hispano y su evolución, Madrid, 1970, 32. La misma idea volvió a repetirla en «Historia», 176.

${ }^{17}$ Al-Rušātī, Kitāb Iqtibās al-anwār, ed. parcial E. Molina López y J. Bosch Vilá, al-Andalus en el Kitāb Iqtibās al-anwār y en el Ijtișār iqtibās al-anwār, Mādrid: CSIC-IHAC, 1990, 59.

${ }^{18}$ Lévi-Provençal, E., Inscriptions arabes d'Espagne, Leyde-París, 1931, n. ${ }^{\circ} 86$.

${ }^{19}$ Barceló, Escritura, I, n. ${ }^{\circ} 1$ y 3.
} 
Almería, resulta muy prematuro que la obra en cuestión estuviese edificada en poco más de un mes. A este respecto, quizá haya que tener en cuenta que el historiador chií Idrīs ' Imād al-Dīn fecha el ataque el viernes $24 \mathrm{rabĭ}^{c}$ I $343 / 28$ julio 954 , es decir, un año antes ${ }^{20}$. En este mismo sentido, resulta curioso que, mientras que al-Ḥimyarī fecha la fundación de Almería por 'Abd al-Rạ̣mān III en el 344/955-956, el Dikr adelante la fecha de construcción de la muralla de la ciudad al año 343 (7 mayo 754-26 abril 955) ${ }^{21}$. Creo que, a falta de nuevos testimonios, no habría que descartar que el ataque se produjese en el verano del $343 / 954$ y que las diferentes obras que se llevaron a cabo como consecuencia del mismo, fundamentalmente el amurallamiento de la ciudad y la construcción o la reconstrucción de las atarazanas, se concluyesen durante el año siguiente.

La estructura habitual de este tipo de inscripciones fundacionales en la época omeya, que solían constar de unas fórmulas religiosas de introducción, los datos de quien ordena la construcción, quien la supervisa, el carácter de la misma y la fecha de conclusión de la obra (sin mención del día, sino tan sólo del mes y el año), me hace pensar que no habría más de las ocho líneas que aparecen ahora, si bien, con una anchura mayor que la actual. La eulogia que acompañaría a la mención del califa podría ser, a tenor de las que aparecen en inscripciones de la misma época, ațāla Allāh baqā-hu (¡Dios le haga vivir muchos años!), ayyada-hu Allāh (¡Dios le dé su apoyo!) o $a^{c} a z z a-h u$ Allāh (¡Dios lo honre!).

Fecha: [Segunda mitad del siglo $\mathrm{x}$ o principios del XI].

Definición: Inscripción decorativa en una basa de columna.

Procedencia: Desconocida, aunque podría proceder de la Mezquita Aljama de Almería.

Ubicación: Museo Provincial de Almería. N. ${ }^{\circ}$ de inventario: 28.787.

Materia: Mármol blanco.

${ }^{20}$ Idrīs 'Imād al-Dīn, ' $U y \bar{u} n$ al-ajbār, ed. parcial Muhammad al-Ya 'lāwī, Ta'rỉj al-julafă' alfătimiyyin bi-l-Magrib, Beirut, 1985, 581-583. Ese año también es el ofrecido en el Kitäb al- ${ }^{c} U y \bar{u} n$ wa-l-hadā'iq fi ajbār al-haqā'iq, ed. Omar Saidi, tomo IV: «Extraits relatifs à l'Occident Musulman et en particulier à l'Ifrīiya (256-350 A: H.)», Les Cahiers de Tunisie, 79-80 (1972), 45100; y 81-82 (1973), 73-122, 92. Sin embargo, aparte de los autores ya mencionados, Ibn al-Atīr, al-Kämil fi l-ta'rỉj, 13 vols., Beirut, 1965-67, VIII, 512-513, lo enmarca en el año 344.

${ }^{21}$ Al-Himyarī, Kitāa al-Raw ḍ al-mi 'țâr, ed. Ihsān 'Abbās, Beirut, $1980^{2}\left(1975^{1}\right)$, 537; y Dikr bilāe al-Andalus, ed. y trad. Luis Molina, Una descripción anónima de al-Andalus, 2 vols., Madrid, 1983, 68 . 
Forma: En una banda que circunda la parte interior de una basa de columna. Medidas: A $16 \mathrm{~cm}$ x L $24 \mathrm{~cm} \times \mathrm{G} 17,5 \mathrm{~cm}$.

Número de líneas: 1 .

Tipo de letra: Transición entre el cúfico florido y el cúfico simple.

Conservación: Se trata de un fragmento con menos de la mitad de la basa. La inscripción, que se encuentra en una cavidad de $4,5 \mathrm{~cm}$ de altura, está bastante desgastada. La inscripción está inserta entre dos franjas de decoración: un cordón sencillo en la superior y una banda de escamas en la inferior. La base presenta en una cara una banda con decoración en triángulos y con hojas de palma en sus espacios internos y en la otra una cenefa de roleos rematados en una cuatrifolia separados por hojas en forma de gotas de agua.

Bibliografía: Inédita.

Texto:

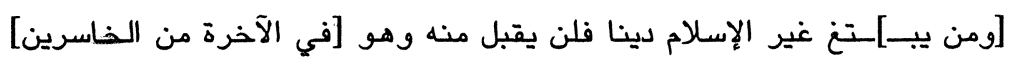

\section{Traducción:}

[Si alguien de]sea una religión diferente del Islam, no se le aceptará y [en la otra vida será de los que pierdan] (Corán, III, 85)

\section{Comentario:}

Dadas las características epigráficas, podría datar de la época califal, en concreto de la segunda mitad del siglo X, o principios de las taifas. Quizá podría proceder de la Mezquita Aljama de Almería, la actual Iglesia de San Juan, parte de cuyos restos, entre ellos fragmentos de yeserías con epigrafía, fueron trasladados a la Alcazaba. Sabemos que dicha mezquita fue construida durante el califato, ampliada al comienzo de las taifas y reformada en época almohade, ante los destrozos efectuados durante el decenio de dominación cristiana. Podría corresponder, por tanto, al período constructivo inicial o bien a la ampliación que realizó Jayrān en el año 410/1019-1020,

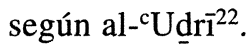

\footnotetext{
${ }^{22} \operatorname{Tarṣīc}^{c}$ al-ajbār, ed. 'Abd al-'Azīz al-Ahwānī, Nuṣūṣ 'ani l-Andalus min kitāb Tarṣī ' al-ajbār wa-tanwì ‘ al-ātāar wa-l-bustān fi garā'ib al-buldān wa-l-masālik ilà ŷamì al-mamālik, Madrid, 1965, 83; trad. M. Sánchez Martínez, «La cora de Ilbīra en los siglos X y XI, según al-'Udrī», Cuadernos de Historia del Islam, 7 (1975-76), 5-82, 36. Ibn al-Jațỉb ( $A^{c}$ mäl al-áclām, parte II, ed. E. Lévi-Provençal, Histoire de l'Espagne musulmane, Beirut, 1956 [Rabat, 1934], 216) atribuye esa ampliación a Zuhayr en lugar de a Jayrān, pero creo que, en este caso, tiene más credibilidad el testimonio del geógrafo almeriense, contemporáneo a los hechos.
} 


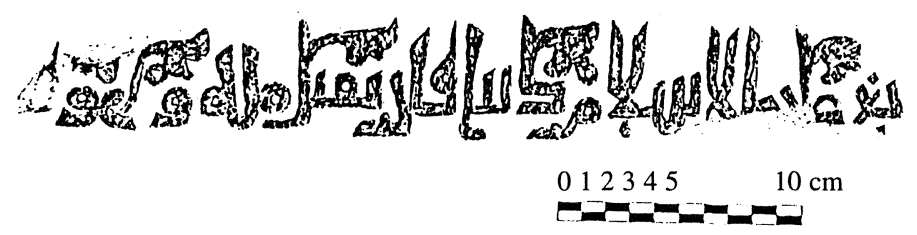

N. ${ }^{\circ} 3$ (Segunda mitad del X o principios del XI).

La inscripción coránica utilizada en la basa había sido utilizada por los gobernantes malikíes norteafricanos contra las dinastías heterodoxas de los bargawāta y los fatimíes, en las monedas acuñadas por ellos. También consta su uso en al-Andalus, en particular durante el siglo XI, tanto en contextos numismáticos, como en otros diferentes; así el alfaquí Abū 1-Walīd al-Bāŷī, muerto en Almería en el 474/1081, utilizó esta aleya coránica en diversos escritos suyos. Pero fueron los almorávides los que hicieron un mayor uso de la misma en los célebres dinares que acuñaron, en sustitución de la habitual proclamación de la misión profética (Corán, IX, 33 o LXI) ${ }^{23}$.

Fecha: [Siglo XI]

Definición: Epitafio.

Procedencia: Desconocida.

Ubicación: Museo Provincial de Almería. N. ${ }^{\circ}$ de inventario: 82.388.

Materia: Mármol blanco.

Forma: Probablemente rectangular alargada.

Medidas: A $42 \mathrm{~cm}$ x L $21 \mathrm{~cm}$ x G $6 \mathrm{~cm}$.

Número de líneas: 6 , incompletas.

Tipo de letra: Cúfica simple.

Conservación: Fragmento superior central, muy deteriorado por todos sus bordes, afectando el deterioro también a la escritura. En la parte superior aparecen motivos almenados.

${ }^{23}$ Sobre todo ello, véase Kassis, H. E., «La moneda, pesos y medidas», en M. ${ }^{a}$ J. Viguera (coord.), El retroceso territorial de al-Andalus. Almorávides y almohades. Siglos XI al XIII, vol. VIII-II de Historia de España, Madrid: Espasa Calpe, 1997, 307-308. Debo esta referencia a la amabilidad de la profesora Viguera. 
Bibliografía: Inédita.

Texto:

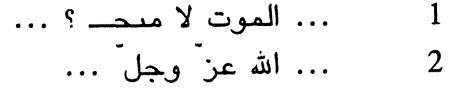

$$
\begin{aligned}
& 3 \\
& \text { } 4
\end{aligned}
$$

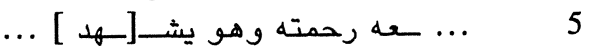

$$
\begin{aligned}
& 6
\end{aligned}
$$

Traducción:

| ... la muerte ... ? ... I ... Dios — - ihonrado y ensalzado sea! - ... $\left.\right|^{3} \ldots$ de sus

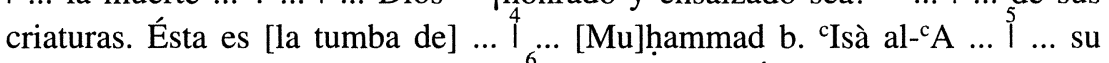
misericordia, mientras atestiguaba ... 1 ... respecto de Él Sus ángeles ...

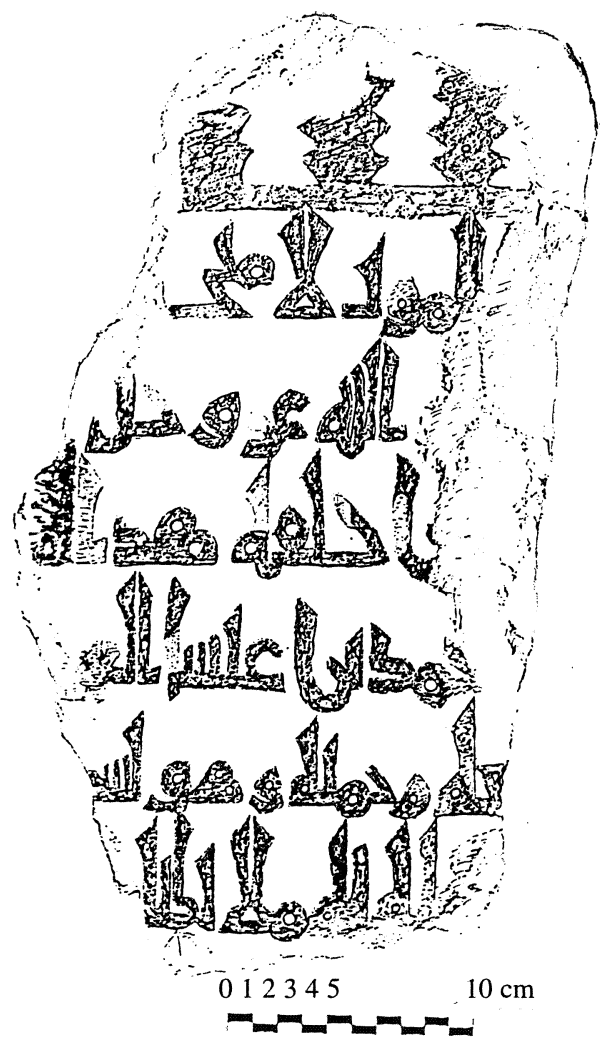

N. ${ }^{\circ} 4$ (Siglo XI). 


\section{Comentario:}

Resulta un epitafio muy extraño, por cuanto que, además de no comenzar con la basmala, lo que me hace pensar que iría acompañada esta estela de otra inscripción que llevaría a aquella como inicio, no aparece tampoco la fecha del óbito entre el nombre y la šahāda, como es habitual. Seguramente esta última tenía la siguiente introducción, al igual que en las n. ${ }^{\circ} 32$ (año 510/1116), 103 (540/1145), 116 (504/1110) y 118 (526/1132) del Repertorio de Ocaña:

وهو يشهد لله بما شهد لنفسه وشهدت له به ملائكته [ورسله / و الرسول] وأولوا العلم من خلقه أنته (أله

«mientras atestiguaba respecto de Dios lo que Él atestigua de Sí mismo y lo que atestiguan respecto de Él Sus ángeles [, Sus profetas/el profeta] y Sus criaturas dotadas de ciencia, que ...».

Pese a que, en todos los casos, la anterior fórmula aparece usada durante la primera mitad del siglo XII, diversos rasgos arcaizantes hacen que me decante por datarla en el siglo XI.

Fecha: [¿Siglo XI?]

Definición: Inscripción decorativa.

Procedencia: Desconocida.

Ubicación: Museo Provincial de Almería. N. ${ }^{\circ}$ de inventario: 82.515.

Materia: Mármol blanco.

Forma: Rectangular apaisada.

Medidas: A $12 \mathrm{~cm}$ x L $20 \mathrm{~cm}$ x G $5 \mathrm{~cm}$.

Número de líneas: 1 .

Tipo de letra: Cúfico simple, con estilización vegetal.

Conservación: Fragmento muy deteriorado, habiendo afectado el deterioro a todos los lados. La inscripción debía de estar enmarcada entre dos bandas de contarios, de las que tan sólo es visible una, la superior.

Bibliografía: Inédita.

\section{Comentario:}

Dado que se trata de un fragmento muy pequeño e incompleto, incluso por la parte inferior de la única línea de escritura, me abstengo de ofrecer una posible lectura y traducción. En relación con la fecha, tampoco puedo ser muy preciso a la vista de lo conservado. 


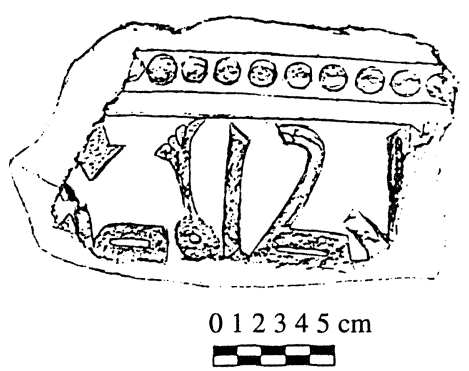

N. ${ }^{\circ} 5$ (¿Siglo XI?).

Existen otras tres piezas de mármol blanco únicamente con decoración de lazo entrecruzado enmarcado por dos bandas de contarios, alguna de las cuales bien podría formar parte del mismo panel decorativo. Dos de ellas se conservan actualmente en el mismo Museo Provincial, con n. ${ }^{\circ}$ de inventario 28.798 y 28.808 y las siguientes medidas, respectivamente: A $31 \mathrm{~cm}$ x L $37 \mathrm{~cm} \mathrm{x} \mathrm{G} \mathrm{6,5}$ cm; y A $13,5 \mathrm{~cm} \times$ L $21,3 \mathrm{~cm} \times$ G 4,3 cm; el otro, en el Instituto de Valencia de Don Juan, con el n. ${ }^{\circ} 5267$ y las siguientes dimensiones: A $33 \mathrm{~cm} \mathrm{x} \mathrm{L} 51 \mathrm{~cm} \mathrm{x} \mathrm{G}$ $5-7 \mathrm{~cm}$. Si nos fijamos en el tipo de lazo, la pieza n. 28.798 del Museo Provincial y la del Instituto de Valencia de Don Juan presentan el mismo modelo, no así la n. ${ }^{\circ} 28.808$, en la que el lazo resulta menos recargado y con curvaturas más redondeadas. En el n. ${ }^{\circ} 5267$ la banda tiene forma de L, por lo que habría de ir situado, probablemente, junto a una puerta. El n.. 28.798 debe ser uno de los extremos, pues la banda de contarios se cierra por su parte izquierda.

Fecha: [Segunda mitad del siglo XI]

Definición: Inscripción decorativa.

Procedencia: Desconocida.

Ubicación: Museo Provincial de Almería. N. ${ }^{\circ}$ de inventario: 29.765.

Materia: Mármol blanco.

Forma: Rectangular apaisada.

Medidas: A $9 \mathrm{~cm} \times \mathrm{L} 20 \mathrm{~cm} \times \mathrm{G} 3,5 \mathrm{~cm}$.

Número de líneas: 1 .

Tipo de letra: Cúfico simple, con motivo floral.

Conservación: Se trata de un pequeño fragmento muy deteriorado. 
Bibliografía: Inédita.

Texto:

Traducción:

...seleccionado (?) ...

\section{Comentario:}

Dado que se trata de una sola palabra resulta muy arriesgado precisar la cronología, aunque creo que podría datar de la segunda parte de las taifas.

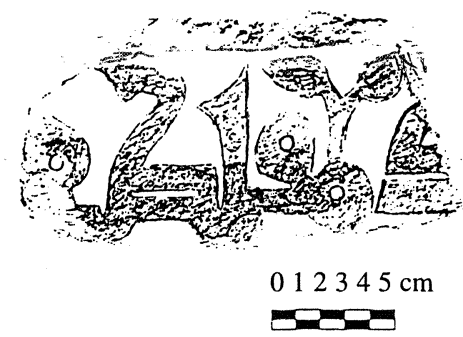

N. ${ }^{\circ} 6$ (Segunda mitad del XI).

Fecha: [Finales del siglo XI-principios del XII]

Definición: Epitafio.

Procedencia: Desconocida.

Ubicación: Museo Provincial de Almería. N. ${ }^{\circ}$ de inventario: 28.805.

Materia: Mármol blanco.

Forma: Rectangular alargada, con faja de enmarque, probablemente por tres de sus lados.

Medidas: A $48 \mathrm{~cm} \times \mathrm{L} 39,5 \mathrm{~cm} \times \mathrm{G} 4 \mathrm{~cm}$.

Número de líneas: 9 líneas (cuatro de ellas completas y cinco incompletas) y restos de otra más, además de 2 líneas incompletas en la faja del recuadro.

Tipo de letra: Cúfico simple.

Conservación: Dos fragmentos, ahora unidos, que son la parte inferior y la parte central derecha de la lápida. 
Bibliografía: Inédita.

Texto:

Faja del recuadro:

$$
\begin{aligned}
& \text { بسم اله الرحمن الرحيم والحمد لله رب العالميـ[ـن] ... } \\
& \text {... عمل مهـ....ـل. }
\end{aligned}
$$

Campo epigráfico central:

$$
\begin{aligned}
& \text { [توفتي ... و وهو يشهد] } \\
& 1 \\
& 2 \\
& 3 \\
& 4 \\
& 5 \\
& 6 \\
& 7 \\
& 8 \\
& 9
\end{aligned}
$$

\section{Traducción:}

Faja del recuadro:

En el nombre de Dios, Clemente y Misericordioso. ¡Alabado sea Dios, Señor del Universo! ... / ... Es obra de M...1.

\section{Campo epigráfico central:}

$9^{0}$ [Murió ... mientras atestiguaba] | que no hay más dios que Dios, [único, sin compañe] I I ro; que Muhammad es Su si[ervo y Su enviado, a qui] I l en ha mandado con la Dirección y con [la religión verdadera para que prevalezca] sobre toda otra religión, a [despecho de los asociadores], (Corán, IX, 33) I ; que el Paraíso es verdad y que [el Fuego es verdad; que la] $\mid$ Resurrección es verdad; que la Hora llega, no hay duda 1 de ella, y Dios resucitará a quienes se encuentren en las sepulturas (Corán, XXII, 7). I En esta confesión vivió, mulrió y volverá a vivir, si Dios quiere.

\section{Comentario:}

En la clasificación que estableció Ocaña de las inscripciones funerarias almerienses parece tratarse de una estela del tipo 3, esto es, aquellas que constan de un campo epigráfico central y tres fajas que lo delimitan. La más antigua de las conocidas en Almería data del último tercio del siglo Iv/finales del $\mathrm{x}$, 


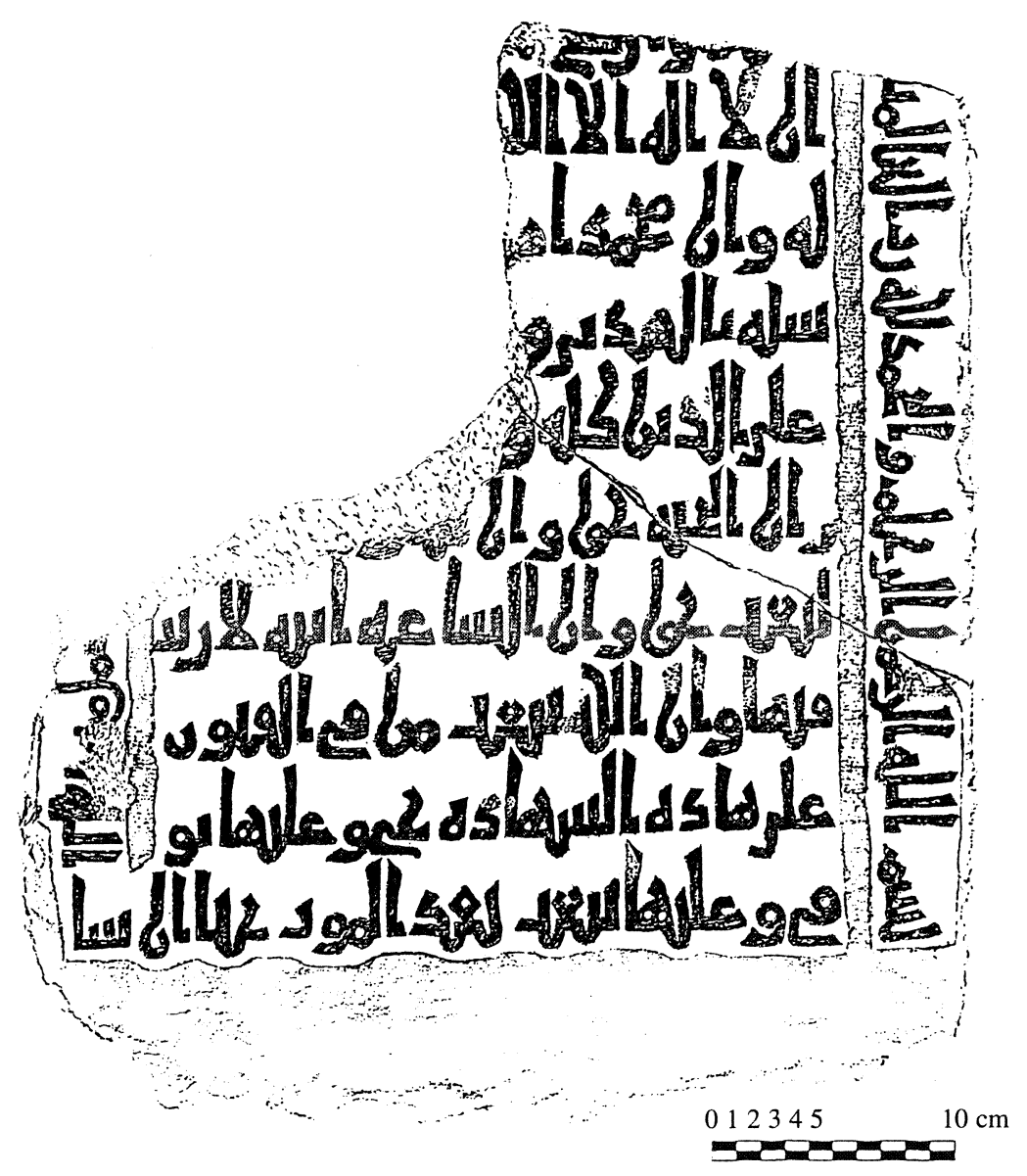

N. ${ }^{\circ} 7$ (Finales del XI-principios del XII).

según Ocaña, y la más reciente es del 505/1112, en el caso de Almería capital, y del 517/1123, en la provincia; en este último caso se trata de una inscripción de Dalías ${ }^{24}$. No obstante, dado que no aparece la mitad superior, también podría ir adornada con el característico arco simbólico.

Resulta llamativo que la inscripción comience en la faja del recuadro, lo que no solía ser frecuente (en el caso de que sea del tipo 3 sería la primera que aparece), y

${ }^{24}$ Ocaña, Repertorio, inscripciones n. ${ }^{\circ} 9,28$ y 117 , respectivamente. 
más aún que a la basmala le siga inmediatamente después la ḥamdala, combinación ésta que es la primera vez también que se documenta en las estelas almerienses.

Lo más relevante de esta inscripción es que aparece firmada, si bien el deterioro sufrido por la pieza ha afectado al nombre del tallista ( ${ }^{c}$ amal $M$...l). Es muy probable que se trate del mismo $\mathrm{Mu}$ 'ammal que aparece en otras dos inscripciones, que datan del 510/1116 (n. 8 de las aquí estudiadas) y 514/1120 (Ocaña, Repertorio, n. $^{\circ} 33$ ).

Lamentablemente, no se ha conservado la fecha, que iría, seguramente, en las dos líneas inmediatamente anteriores al fragmento conservado. En los restos que se observan de una de esas líneas podría leerse wa-arbaci... referido, probablemente, a la centuria. De ser cierta esta observación, habría de ser anterior al 499/1105-6.

Esta pieza fue mostrada en la Exposición sobre Cultura Islámica en España, celebrada en Toledo en abril-mayo de 1987, así como en el Pabellón de Andalucía de la Expo'92 (20 abril-12 octubre 1992) en «La memoria productiva», sin que me conste que haya sido estudiada.

\section{8}

Fecha: La vela del lunes, 21 de muharram $510=5$ junio 1116.

Definición: Epitafio.

Procedencia: Desconocida.

Ubicación: Museo Provincial de Almería. N. ${ }^{\circ}$ de inventario 28.790 y 28.791.

Materia: Mármol blanco.

Forma: Mqābrīya.

Medidas: A $15 \mathrm{~cm}$ x L $66 \mathrm{~cm}$ x G $24 \mathrm{~cm}$; y A 14,5 cm x L $66 \mathrm{~cm}$ x G 23,5 cm.

A tenor del texto que falta, la mqābrìya podría tener una longitud total de $1,42 \mathrm{~m}$, aproximadamente.

Número de líneas: 1 por cara en cada frente y 2 en cada uno de los triángulos de los costados.

Tipo de letra: Cúfico simple.

Conservación: Dos fragmentos que corresponden a los dos extremos, faltando únicamente un fragmento central de unos 19-22 cm para que la inscripción esté completa. El estado de conservación, en general, es bueno, leyéndose claramente la inscripción, salvo algunos desperfectos en las aristas y un mayor desgaste de la base del triángulo del costado derecho.

Bibliografía: Inédita. 


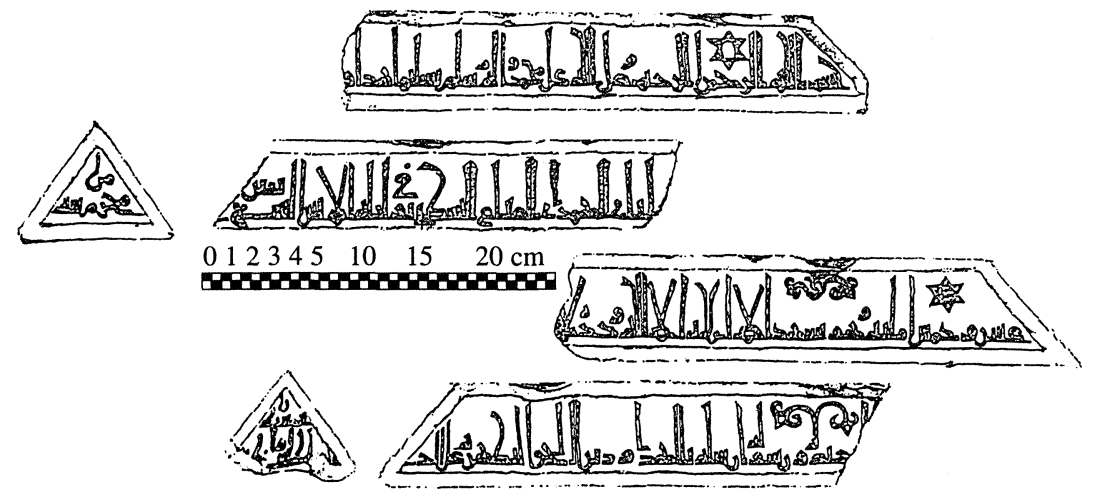

N. ${ }^{\circ} 8(510 / 1116)$. Los dos fragmentos extremos conservados.

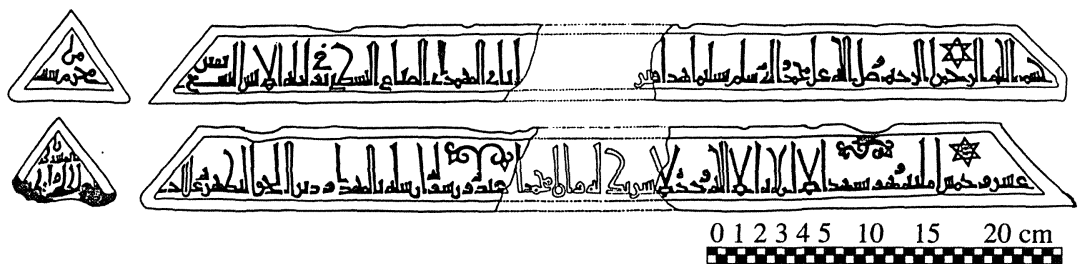

N. ${ }^{\circ} 8$ (510/1116). Reconstrucción.

Texto:

Frente anterior:

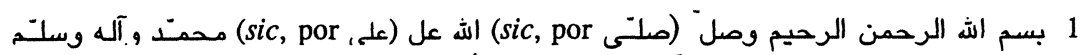

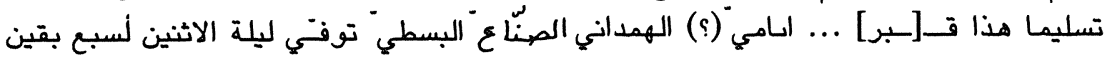

Triángulo del costado izquierdo:

Frente posterior:

$$
2 \text { من محر م سنة }
$$

3 عشر وخمس مائة وهو يشهد ألاً إله إلآ اله وحده لا [شريك له وأن محمـدا]] عبده ورسوله

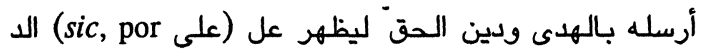

Triángulo del costado derecho:

$$
4 \text { ين كته ولو كره المشركين. }
$$




\section{Traducción:}

I En el nombre de Dios, Clemente y Misericordioso. ¡Dios bendiga a Muhammad y a su familia y los salve! Ésta es la t[umba de] ... ā.āmī alHamdānī, el artesano, de Baza (al-Bastīi). Murió la noche del lunes, quedando siete noches 1 de muharram del año $\left.\right|^{2}$ diez y quinientos, mientras atestiguaba que no hay más dios que Allāh, único, [sin compañero y que Muhammad] es Su siervo y Su enviado a quien ha mandado con la Dirección y con la religión verdadera para que prevalezca sobre 4 toda otra religión, a despecho de los asociadores (Corán, IX, 33).

\section{Comentario:}

Lo más llamativo de esta inscripción es la aparición, por dos veces, de una estrella de seis puntas o del sello de Salomón, una en cada frente. Se trata de un símbolo de origen mesopotámico con valor profiláctico que no hay que relacionar, en este caso, con elementos judíos ${ }^{25}$.

En el interior de una de esas estrellas se lee claramente ${ }^{c}$ amal Mu'ammal (obra de Mu'ammal). Se trata del único tallista conocido de Almería, aparte de un no seguro Sucāt (Ocaña, n. ${ }^{\circ} 71$ ), que quizá habría que leer Sucād. La única mención anterior que era conocida figura en una inscripción del 514/1120, es decir cuatro años posterior a ésta (Ocaña, $n .^{\circ} 33$ ). En relación con esa otra inscripción, de carácter fundacional de legados píos, Ocaña comentó que «está plagada de incorrecciones por impericia del tallista». Ello resulta totalmente válido para esta otra inscripción, pues se observan deficiencias en el trazo de algunas letras, tales como la mala trabazón de la hạa' y la qăf en al-ḥaqq o la palabra ilăh. La falta de alif maqsūra en sallà y calà es algo frecuente en la epigrafía andalusí ${ }^{26}$. También resulta llamativo el que diversas letras vayan en la parte superior de la línea. Recuérdese que la inscripción $n .^{\circ} 7$ de este estudio también podría ser obra suya.

De acuerdo con las múltiples inscripciones en las que aparece la misma fórmula de la šahā $d a$, he restituido las palabras que faltan en una de las caras, aunque podría darse el caso de que la laguna fuese mayor, siguiendo el ejemplo de las inscripciones n. 53 (año 520/1126) y 103 (año 540/1145), también

\footnotetext{
${ }^{25}$ Representa la esquematización de un ojo (triángulo), susceptible de ser atacado por el mal de ojo, en conjunción con su antítesis (el triángulo opuesto), que invalida cualquier intento de maleficio. Cf. Zozaya, J., «Cerámicas islámicas del Museo de Soria», Boletín de la Asociación Española de Orientalistas, XI (1975), 135-148; y Souto Lasala, J. A., «Algunos signos mágicos musulmanes en la cerámica "verde y morada" de Teruel (siglos XIII-XIV)i, Actes du Colloque International de Glyptographiques de Saragosse, 1982, 466.

${ }^{26}$ Cf. Barceló, C., Escritura, I, 101.
} 
de Almería, en las que se añade: lā šarìka la-hu ŷabbār al-ŷabāriba wa-qayyūm al-dunyā wa-l-äjira wa-anna Muḥammad ${ }^{a n}$...; o la n. ${ }^{\circ} 118$ (año 526/1132) del mismo repertorio en la que se puede leer: lā šarika la-hu fard samad wa-anna Muhammad ${ }^{a n}$...

Lamentablemente, resulta imposible reconstruir el nombre del difunto del que tan sólo sabemos su nisba tribal, al-Hamdānī; su nisba geográfica, al-Basțī, es decir, originario de Baza; y su laqab de profesión, al-șanna $\bar{a}^{c}$, el artesano.

Fecha: [¿Primer cuarto del siglo XII?]

Definición: Epitafio.

Procedencia: Desconocida.

Ubicación: Museo Provincial de Almería. N. ${ }^{\circ}$ de inventario: 28.806.

Materia: Mármol blanco.

Forma: Rectangular alargada, con faja de enmarque y, probablemente, con arco de herradura.

Medidas: A $38 \mathrm{~cm}$ x L $25,5 \mathrm{~cm}$ x G $4 \mathrm{~cm}$.

Número de líneas: Los inicios de 9 líneas y los trazos superiores de una décima, además de 1 línea en la faja del recuadro, también incompleta.

Tipo de letra: Cúfico simple.

Conservación: Fragmento de la parte central derecha, deteriorada por los bordes, aunque los trazos de las letras están bien conservados, salvo el principio de la línea de la faja del recuadro, cuyos caracteres están muy desgastados.

Bibliografía: Inédita.

Texto:

Campo epigráfico central:

$$
\begin{aligned}
& 1 \\
& 2 \\
& 3 \\
& 4 \\
& 5 \\
& 6 \\
& \text { أ } 7 \\
& 8 \\
& 9
\end{aligned}
$$


Faja del recuadro:

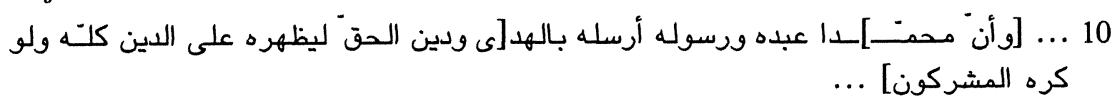

\section{Traducción:}

Campo epigráfico central:

1 ... y acreciente ... I ... los impíos ... I y Él es el más rápido en ajustar cuentas (Corán, VI, 62, final) ... [Ésta] l es la sepultura del jerife, pre[dicador(?)] ... I ? ... I Manșūr Ibn Idrīs ... I b. Ahmad b. al-Qā[sim] ... I b. b. 'Ubayd Allāh b. ... I b. Idrīs b. ${ }^{\mathrm{c} U b}$ [ayd ( ) o ${ }^{\mathrm{c}} \mathrm{Abd}$ ?) Allāh] ...

\section{Faja del recuadro:}

1 [y que Muham]mad es Su siervo y Su enviado, al que envió con la Dirección [y con la religión verdadera para que, a despecho de los asociadores, prevalezca sobre toda otra religión] (Corán, IX, 33).

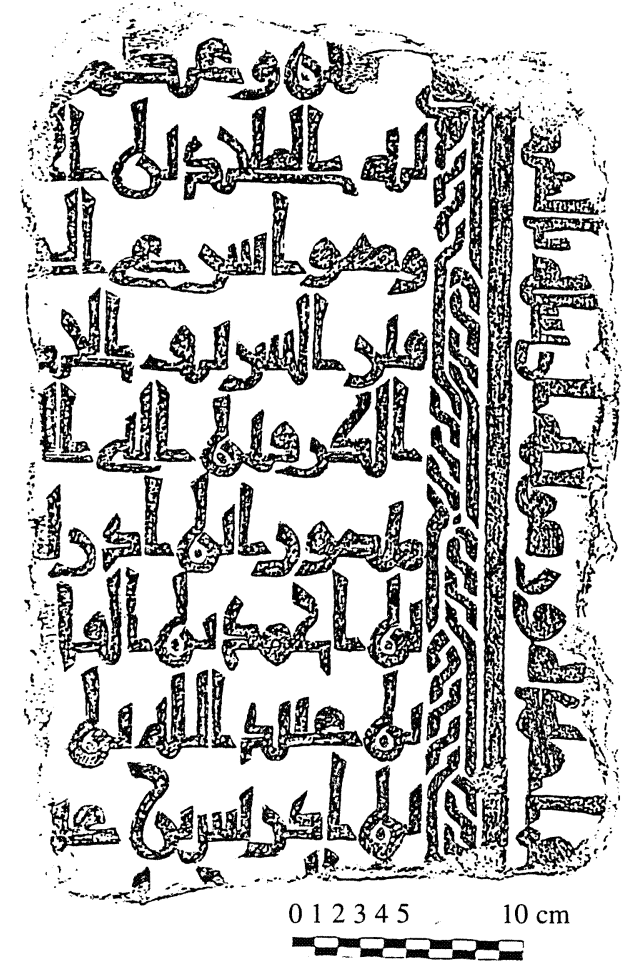

N. ${ }^{\circ} 9$ (¿Primer cuarto del XII?). 


\section{Comentario:}

La lectura del epitafio de este importante personaje, a juzgar no sólo por el calificativo al-šariff, sino también por la larga cadena de ansāb en su nombre, presenta algunas dudas dado que sólo se conserva la mitad, aproximadamente, de cada línea del fragmento, sin que aparezcan fórmulas usuales, salvo quizá en la primera línea: 'azz̧ama [Allāh aŷra-hu] (¡acreciente Dios su recompensa!), cuya forma verbal suele aparecer con el esquema af ala en lugar de $\mathrm{fa}^{c c}$ ala. No he encontrado ninguna interpretación a la palabra al-karfin o al-karqin; quizá se trate de un error y sea al-Käfirìn, con el mismo sentido que al-mulhidìn, aunque para ello habría que contar con importantes errores del tallista. Si realmente la palabra siguiente es el relativo allati, como he interpretado, hay que considerar que exista un estado constructo anterior con el primer término en femenino.

Las dudas también afectan a la cronología, pues las características epigráficas son muy dispares. La más peculiar es la representación de la dāl, con apéndice tanto superior como inferior; su forma es muy similar a la que aparece en la inscripción almeriense número 34 , que Ocaña propone fechar en el 515/1121.

El tipo de estela parece ser el n. ${ }^{\circ} 4$ de la clasificación establecida por Ocaña, con arco de herradura simbólico que remata el campo central de escritura. En la parte superior del fragmento parece observarse el arranque del arco. La inscripcion más antigua conservada en toda al-Andalus con este arco de herradura es la almeriense n. ${ }^{\circ} 32$ del Repertorio de Ocaña, que data del 510/1116.

La decorativa cadena formando un cordón con motivos en forma de $\mathrm{S}$ (cordón de la eternidad), que acompaña al filete que separa la faja de enmarque del campo epigráfico central, parece ser una muestra más de la relevancia del personaje.

Fecha: [Tercera década del siglo XII]

Definición: Quizá una tabica funeraria.

Procedencia: Desconocida.

Ubicación: Museo Provincial de Almería. N. ${ }^{\circ}$ de inventario: 28.804.

Materia: Mármol blanco.

Forma: Rectangular apaisada.

Medidas: A $15 \mathrm{~cm}$ x L $20 \mathrm{~cm}$ x G $3 \mathrm{~cm}$. 


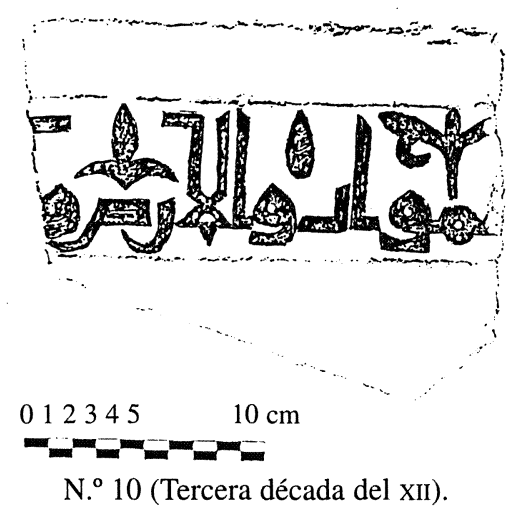

Número de líneas: 1.

Tipo de letra: Cúfico simple, con motivos florales.

Conservación: Se trata de un fragmento, aunque bien conservado. La parte superior parece ser el borde.

Bibliografía: Inédita.

Texto:

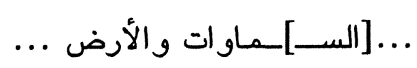

Traducción:

... los cielos y la tierra...

\section{Comentario:}

Podría tratarse de una aleya coránica, quizá la VII, 54, en la que se alude a Dios como creador de los cielos y la tierra en seis días, o con mayor probabilidad la II, 255, en la que se señala que «Su Trono [refiriéndose a Dios] se extiende sobre los cielos y sobre la tierra y su conservación no le resulta onerosa». La primera aleya aparece en una mqābrīya almeriense de la cuarta década del siglo $\mathrm{VI} /$ mediados del XII (Ocaña, Repertorio, n. ${ }^{\circ} 88$ ) y la segunda en otras dos $m q \bar{a}$ briyas almerienses de la primera y segunda década del siglo VI/1107-1126 (Ocaña, Repertorio, n. 30 y 43).

La forma puntiaguda de la letra wāw es muy característica del siglo XII. Para la precisión cronológica me he basado, fundamentalmente, en la forma del nexo lām-alif, que resulta muy semejante a la que aparece en inscripciones también almerienses de los años 516/1122 y 520/1126. 
Fecha: Lunes, 27 de šawwāl del $528=20$ agosto 1134 .

Definición: Epitafio.

Procedencia: Desconocida.

Ubicación: Museo Provincial de Almería. N. ${ }^{\circ}$ de inventario: 28.792 y 28.794.

Materia: Mármol blanco.

Forma: Mqābrīya.

Medidas: A $13 \mathrm{~cm}$ x L $148 \mathrm{~cm} \mathrm{x} \mathrm{G} \mathrm{20,5} \mathrm{cm.}$

Número de líneas: 7 (una línea en cada uno de los tres tarjetones y dos líneas en cada uno de los triángulos laterales).

Tipo de letra: Cúfico simple.

Conservación: La mqābrīya, aunque completa, está fragmentada en dos piezas, habiendo sufrido un importante deterioro en la arista superior.

Bibliografía: Inédita.

Texto:

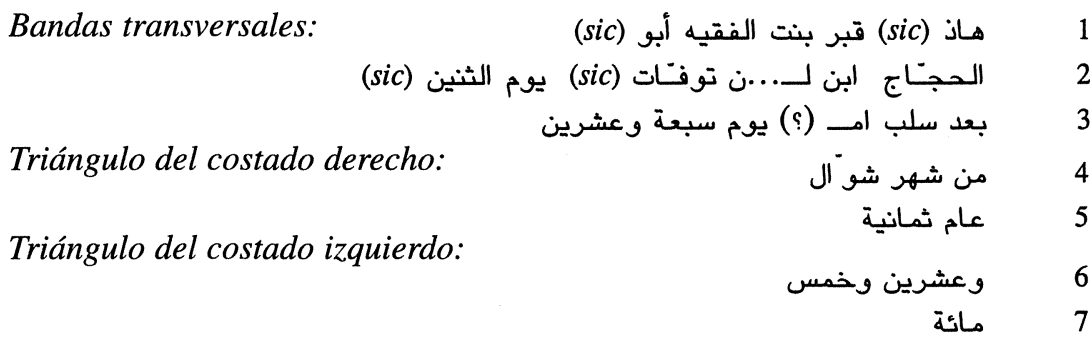

Traducción:

I Esta es la sepultura de la hija del alfaquí Abū I l-Hậŷâây Ibn L...n. Murió el lunes, $\left.\right|^{3}$ después de ...(?), el $27 \mid 4$ del mes de šawwäl $\mid$ del año ocho $\mid$ y veinte y quinilentos (20 agosto 1134).

\section{Comentario:}

Resulta sumamente llamativa la disposición de la inscripción en tres tarjetones transversales perpendiculares, además de los dos triángulos laterales, quedando el resto liso. Esos tarjetones transversales guardan simetría: 49,5 cm entre ellos y $7 \mathrm{~cm}$ entre los tarjetones extremos y el punto superior de los costados. Esta curiosa disposición, no documentada antes en Almería, ha hecho que, por el deterioro sufrido en la arista superior, resulte muy difícil, cuando no imposible, la lectura de las partes centrales. 

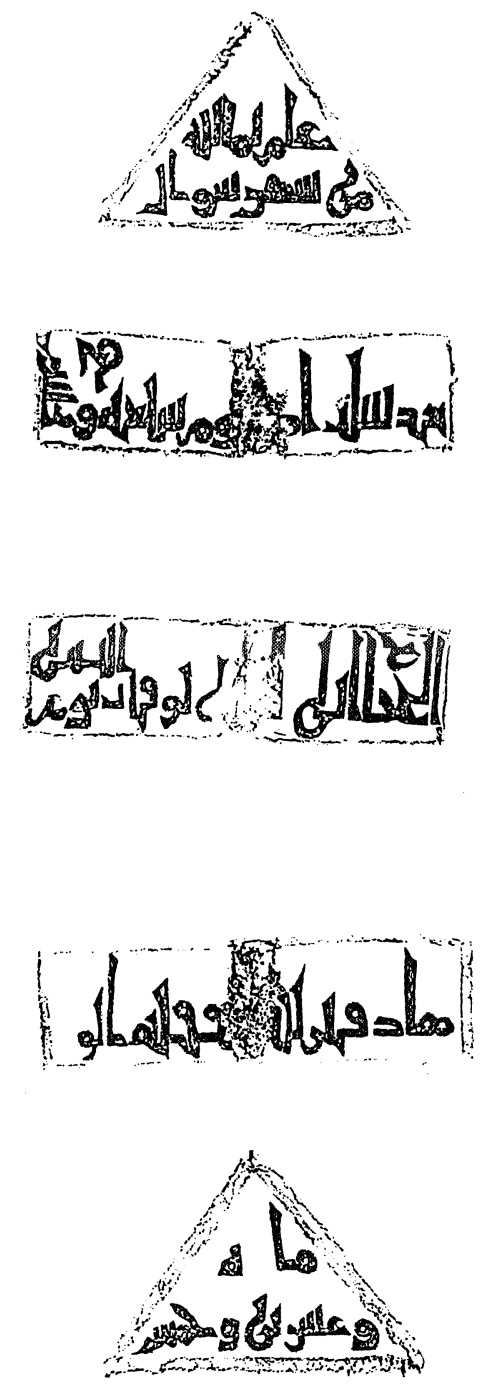

012345 $10 \mathrm{~cm}$

N. ${ }^{\circ} 11(528 / 1134)$.

Son numerosos los rasgos lingüísticos curiosos, tales como la supresión del alif final en la palabra $h \bar{a} \underline{d} \bar{a}$, en la que, sin embargo, marca el alif de la $h \bar{a}$ ', que normalmente aparece abreviado; la supresión también del alif en al-itnayn y de 
la grafía correspondiente a la hamza en mi'a, en la que ha dejado el hueco; y la conversión de la $y \bar{a}$ ' en alif en tuwuffiyat. Asimismo, llama la atención los diversos casos en los que ha tenido que recurrir a utilizar la parte superior de la línea, escribiendo en una ocasión, incluso, en forma de semicírculo. También se documenta una incorrección gramatical al aparecer $A b \bar{u}$ en lugar de $A b \bar{i}$, como correspondería.

Fecha: [¿536/1141-1142?]

Definición: Inscripción conmemorativa de la construcción de una pila de abluciones.

Procedencia: Alcazaba de Almería.

Ubicación: Museo Provincial de Almería. N. ${ }^{\circ}$ de inventario: 28.800.

Materia: Mármol blanco.

Forma: Rectangular apaisada.

Medidas: A $74 \mathrm{~cm}$ x L más de $120 \mathrm{~cm}$ x G 4,5 cm.

Número de líneas: 8 líneas incompletas todas ellas.

Tipo de letra: Cúfico simple

Conservación: Seis fragmentos, de los cuales cinco están unidos y uno queda suelto. En muy buenas condiciones de conservación. Originariamente, estuvo policromada, percibiendo Manuel Ocaña restos de color bermellón en los resquicios de las letras y de azul oscuro en el fondo, restos que hoy en día han desaparecido por completo.

Bibliografía: OCAÑA, 1964: n. 100 y lám. XLIII, a y b (cuatro fragmentos).

Texto:

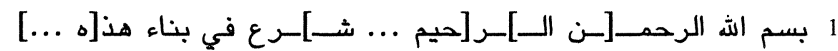

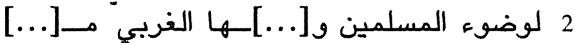

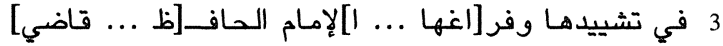

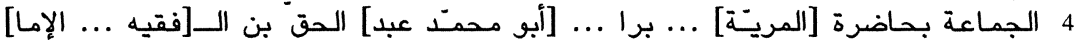

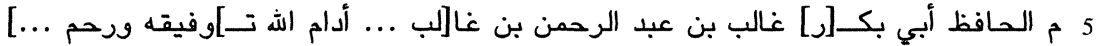

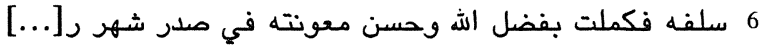

$$
\begin{aligned}
& 7 \text { الإنفاق فيها من وميتّة الفقيه } \\
& 8 \text { نم البوني رحمـ الله ورحم }
\end{aligned}
$$



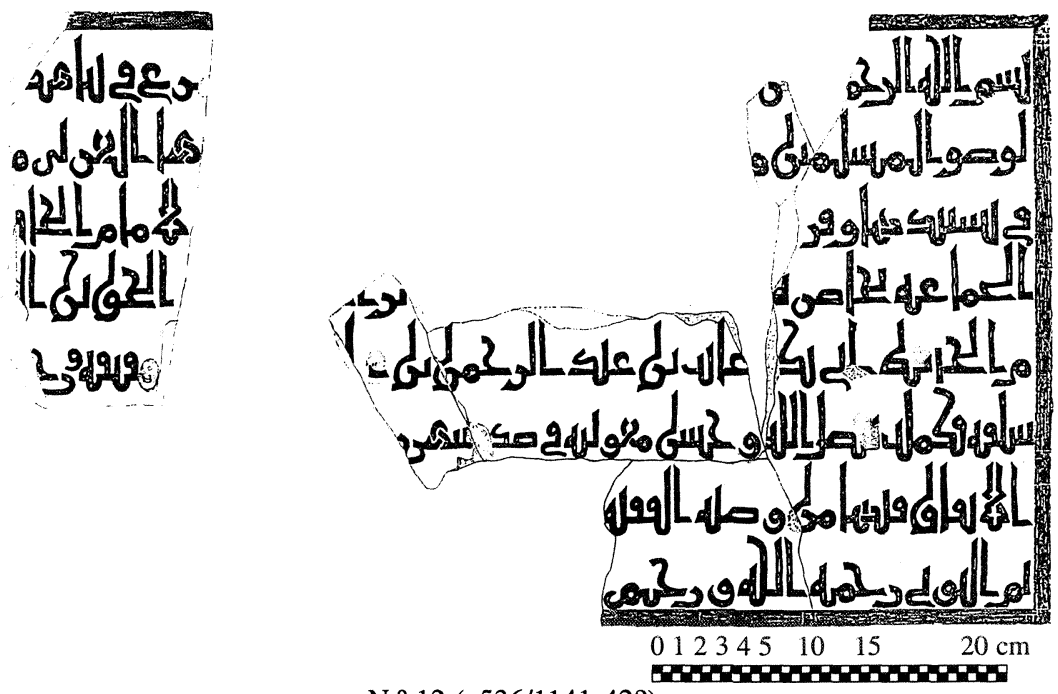

N. ${ }^{\circ} 12(¿ 536 / 1141-42 ?)$.

Traducción:

I En el nombre de Dios, Clemen[te y Mi]se[ricordioso ... Se de]dicó por entero a la construcción de es[ta ...] $]^{2}$ para la ablución de los musulmanes y ... occidental de ella ... I en su erección y terminación ... el imām, hạäi $[z$... cadí Ide la comunidad en la capital [de Almería] ... ? ... [Abū Muhammad 'Abd] alḤaqq, hijo del al[faquí, imālm y ḥăfiz Abū Bak[r] Gālib b. ${ }^{~}$ Abd al-Rahmān b. Gā[lib ... - ¡Dios le prolongue su ayuda y tenga misericordia ...] $\left.\right|^{6}$ de sus antepasados! Fue terminada con el favor de Dios y Su hermosa ayuda a comien[zos] del mes de ra ... ? lo gastado en ella de la manda testamentaria del alfaquí ... $\mid$... m al-Būnī -¡Dios tenga misericordia de él y de...!

\section{Comentario:}

Esta inscripción fue estudiada por Ocaña, a quien hemos seguido en su transcripción y traducción, incorporando los dos nuevos fragmentos inéditos, los más pequeños.

Según señaló Ocaña, «conmemora, sin duda, la construcción de una mị̣̆a'a $a$ (ميضأة) (sic) para la realización de las abluciones rituales ejecutada por orden

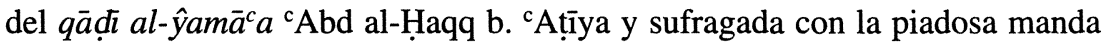
de un faqih, del que sólo se sabe que era originario de Bona (Argelia)».

Dado que la fecha no aparecía en los fragmentos conservados y estudiados por Ocaña, éste hubo de datarla a partir de los rasgos epigráficos, encuadrán- 
dola en la cuarta década del siglo vi de la hégira, es decir entre 1135-1145. Para ello, probablemente, también tendría en cuenta el hecho de que esté a nombre del cadí Abū Muhammad 'Abd al-Haqq Ibn 'Ațīya, del que sabemos que fue nombrado cadí de Almería en muharram del 529/1134, y a cuyo nombre también se esculpió una inscripción conmemorativa con motivo del aumento, en unos cinco metros, de la altura del alminar de la mezquita aljama de Almería en el 531/1136-37 ${ }^{27}$.

En la datación de la inscripción podemos ser más precisos, dado que el alfaquí originario de Bona que sufragó los gastos de la construcción podría ser Abū 'Abd Allāh Muḥammad b. Sulaymān b. Marwān b. Yahyyà al-Qaysī, conocido por al-Būnī, es decir, el de Bona ${ }^{28}$. Sabemos que murió en Almería en șafar del 536/5 septiembre 1141-3 octubre 1141, tras haber vivido en diversas localidades, entre ellas Valencia. Había estudiado también en Córdoba, Sevilla y

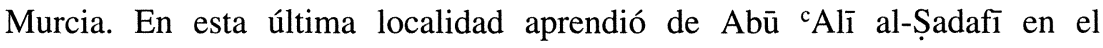
495/1101-1102. Ibn Baškuwāl lo mencionó entre sus maestros.

En uno de los nuevos fragmentos figura la primera letra del mes, que es una $r \bar{a}$ ', por lo que podría tratarse de los meses de $r a b \bar{i}^{c}$ I, $r a b \bar{i}^{c}$ II, $r a \hat{y} a b$ o ramaḍān del año 536/1141-42.

Según precisa Ocaña, los fragmentos estudiados por él fueron descubiertos en el interior del segundo recinto de la Alcazaba, al pie de la muralla meridional, en las excavaciones que se realizaron en el año 1943. Sobre los dos inéditos no disponemos de información alguna, aunque hemos de sospechar que aparecerían en un lugar próximo al del resto.

\footnotetext{
${ }^{27}$ Se trata del cadí Abū Muhammad 'Abd al-Haqq b. Gālib b. 'Abd al-Raḥmān b. Gālib b. 'Abd al-Ra'ūf b. Qāsim b. Tammām b. 'Abd Allāh b. Tammām b. 'Atīya b. Jālid b. 'Atịya b. Jālid b. Jufāf b. Aslam b. Maktūm al-Muhāribī al-Garnāṭ̂i, sobre cuyo nombre, en parte del nasab, difieren sus biógrafos. Nació en Granada en el 481/1088 y murió, según la mayoría de sus biógrafos, en Lorca en ramaḍan de 541/ febrero-marzo de 1147. Algunos retrasan la fecha de su muerte al 542/1147-48 e Ibn al-Jațib precisa que se produjo el 25 de ramaḍān de 546/5 de enero de 1152 . Sobre él, véase al-Dabbī, Bugya, ed. Ibrāhīm al-Abyārī, Beirut-El Cairo, $1989^{2}$, n. ${ }^{\circ} 1106$; alDahabī, Siyar, Beirut, 1985, XIX, n. ${ }^{\circ} 337$; Ibn al-Abbār, Mu'ŷam, ed. al-Abyārī, El Cairo-Beirut, 1989, n. ${ }^{\circ}$ 240; Ibn Baškuwāl, Sila, ed. Ibrāhīm al-Abyārī, El Cairo-Beirut, 1989, n. ${ }^{\circ} 834$; Ibn alJațīb, Iḥătạ, ed. 'Inān, El Cairo, 1975, III, 539-541; Ibn al-Zubayr, Șila, ed. E. Lévi-Provençal, Rabat, 1938, n. ${ }^{\circ}$ 5; al-Nubāhī (por al-Bunnāhī), al-Marqaba, 109; al-Ṣafadī, Wā fi, varios editores, Wiesbaden, 1980, XVIII, n. ${ }^{\circ}$ 61; al-Suyūṭ̂, Bugya, ed. Muḥammad Abū l-Fạ̣l Ibrāhīm, s.l., 1979, II, n. ${ }^{\circ}$ 1470; Fórneas, J. M., «Los Banū 'Ațiyya», II, MEAH, 26 (1977), 27-60; Ortega J. y del Moral C., Diccionario de escritores granadinos (siglos VIII-XX). Granada, 1991, 104-105; y Pons, F., Ensayo bio-bibliográfico sobre los historiadores y geógrafos arábigo-españoles, Madrid, 1898, n. ${ }^{\circ}$ 170. La otra inscripción esculpida a su nombre aparece en Ocaña, Repertorio, n. ${ }^{\circ} 79$.

${ }^{28}$ Aparece biografiado en Ibn al-Abbār, $M u^{\text {‘ }} \hat{y} a m, \mathrm{n} .{ }^{\circ} 115$.
} 
Fecha: [Cuarta década del siglo XII].

Definición: Epitafio.

Procedencia: Depositado por Juan Bretones en marzo de 1963. Decía haberlo encontrado en la calle Trajano.

Ubicación: Museo Provincial de Almería. N. ${ }^{\circ}$ de inventario: 23.556.

Materia: Mármol blanco.

Forma: Rectangular alargada, con faja de enmarque y con arco de herradura. Medidas: A $23 \mathrm{~cm}$ x L 27,5 cm x G $5 \mathrm{~cm}$.

Número de líneas: 5 líneas incompletas más 1 también incompleta.

Tipo de letra: Cúfico simple.

Conservación: Fragmento del lateral derecho, con resto de la faja de enmarque y arranque de la parte derecha del arco de herradura.

Bibliografía: Inédita.

Texto:

Campo epigráfico central:

$$
\begin{aligned}
& 1 \\
& 2 \\
& 3 \\
& \text { } 4 \\
& 5
\end{aligned}
$$

Faja del recuadro:

$$
6 \text { } 6 \text { [... أرسله بالهدى ود]ين الحقّ ليظهر [ه على الدين كته ولو كره المشركون] }
$$

Traducción:

Campo epigráfico central:

... I el Majestuoso y Honorable ... $\left.\right|^{2}$ ¡Hombres! (Lo [que Dios promete es verdad!] ${ }^{3}$;Que no os engañe la vida [de acá! ;Que no os] enlgañe acerca de Dios el Engañador! (Corán, XXXV, 5). [Esta es la tumba de ...] ${ }^{5}$ al-H... alH.s...

\section{Faja del recuadro:}

I [... al que envió con la Dirección y con la reli]gión verdadera para que prevalezca [sobre toda otra religión, a despecho de los asociadores] (Corán, IX, 33). 


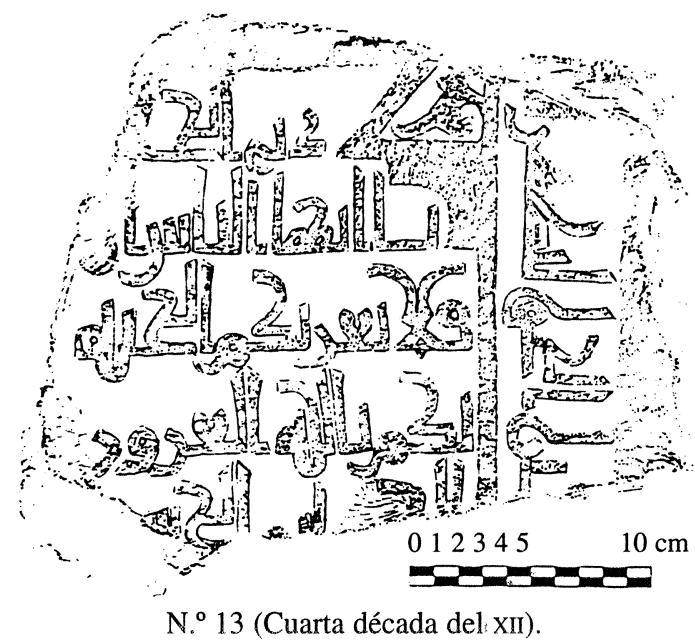

\section{Comentario:}

Se trata, claramente, de una estela del tipo 4 de las establecidas por Ocaña, es decir, con arco de herradura simbólico que remata el campo central de escritura. En Almería, la primera conocida data del 510/1116 y la más tardía del 718/1318.

En la primera línea de las conservadas he desechado leer di l-hîŷya por cuanto que la fecha de óbito no aparece en esa parte de la lápida. Creo que bien podría ser la cita coránica kullu man calay-hā fān ${ }^{i n}$ wa-yabqà waŷhu rabbi-ka d̄i l-yalāl wa-l-ikrām (Todo aquel que está sobre ella (la tierra) es perecedero, pero subsiste tu Señor, el Majestuoso y Honorable) (Corán, LV, 26-27), que no he encontrado en ningún epitafio almeriense ni tampoco del resto de alAndalus, pero que se ajusta al contenido habitual de este tipo de inscripciones y sí se documenta en inscripciones funerarias de otros ámbitos musulmanes ${ }^{29}$.

Seguramente, el fragmento coránico IX, 33 (= LXI, 9), que aparece en la faja de enmarque, seguía a la profesión de fe islámica, del mismo modo que aparece en la mayoría de la inscripciones de este tipo: «murió ... mientras atestiguaba que no hay más dios que Dios, Único, sin asociado, y que Muhammad es Su siervo y Su enviado». La mayor parte de ese texto iría al final del campo epigráfico central.

${ }^{29}$ Así puede comprobarse en las obras de Madeleine Schneider Stèles funéraires musulmanes des îles Dahlak (Mer Rouge), I. Introduction, documents et indices (El Cairo, 1983) y Pierres tombales des Cimetières arabes de Zafär Dỉ Bīn (Estambul, 1988), en las que aparece inmediatamente después de la basmala. 
Fecha: [Segundo cuarto del siglo XII].

Definición: Epitafio.

Procedencia: Desconocida.

Ubicación: Museo Provincial de Almería. N. ${ }^{\circ}$ de inventario: 23.558.

Materia: Mármol blanco.

Forma: Mqābrìya.

Medidas: A $15 \mathrm{~cm}$ x L $35 \mathrm{~cm}$ x G 21,5 cm.

Número de líneas: 4 ( 2 por cara).

Tipo de letra: Cúfico simple.

Conservación: Fragmento central de la mqābrīya, muy deteriorada por la arista superior, aunque sin que el desgaste haya afectado al texto, que está bien conservado.

Bibliografía: Inédita.

Texto:

Frente anterior:

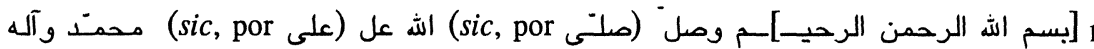
و [سلّم تسليما].... ... . . . . . 2.

Frente posterior:

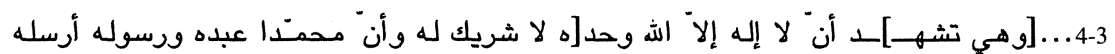

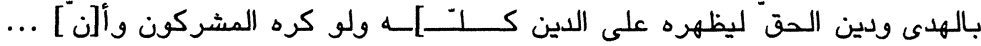

Traducción:

1 [En el nombre de Dios, Clemente y Misericordio]so. Dios bendiga a Muhammad y a su familia y [los salve. ... I ... És]ta es la sepultura de ${ }^{c}$ Azīza bint Ahmad ... [Murió ... I $^{3-. .}$ atestiguan]do que no hay más dios que Dios, úni[co, sin compañero, y que Muhammad es Su siervo y Su enviado, al que envió con la Dirección y con la religión verdadera para que prevalezca sobre toda otra religión], a despecho de los asociadores, (Corán, IX, 33), y que ...

\section{Comentario:}

Para la propuesta de fecha de este epitafio a nombre de una mujer, segundo cuarto del siglo XII, me he basado en las características epigráficas. Creo que, incluso, se podría ser más preciso, apuntando los rasgos a la cuarta década del 

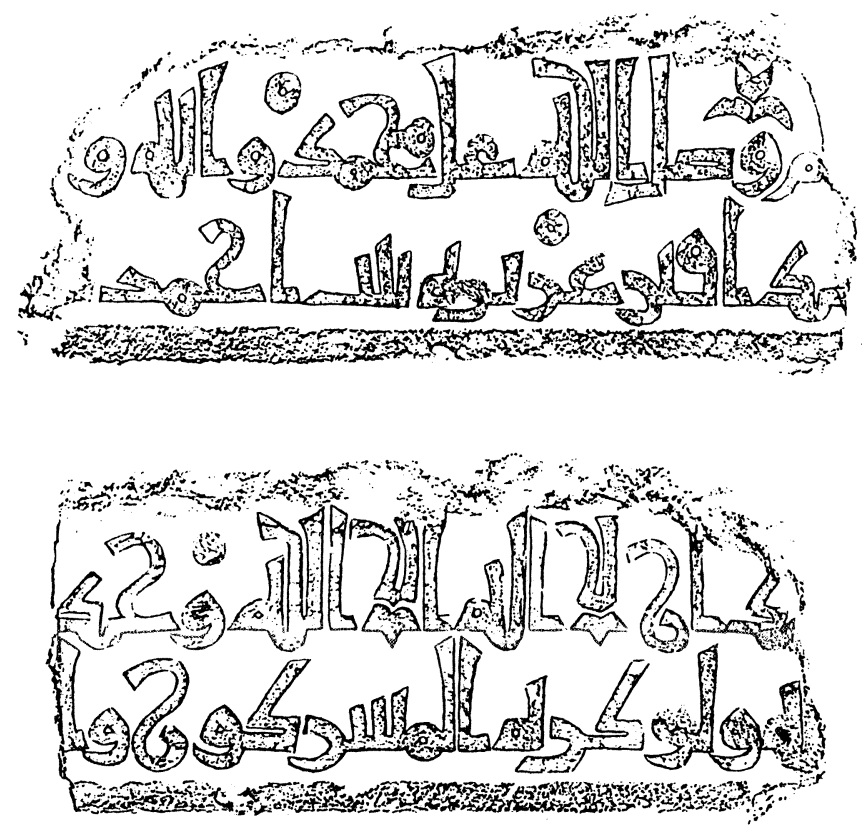

012345

$10 \mathrm{~cm}$

N. ${ }^{\circ} 14$ (Segundo cuarto del XII).

Frentes anterior y posterior de la mqābrīya,

siglo XII, por la similitud con otras inscripciones almerienses de entre los años 525/1131 y 532/1137.

En esta inscripción se constata la falta del alif maqșūra en las palabras șallà $\mathrm{y}^{c}$ alà, frecuente en la epigrafía andalusí, como ya he señalado.

Además de un motivo floral, aparecen tres sukūnes meramente decorativos.

Fecha: [Primera mitad del siglo XII].

Definición: Epitafio.

Procedencia: Desconocida.

Ubicación: Museo Provincial de Almería. ‥ ${ }^{\circ}$ de inventario: 28.813.

Materia: Mármol blanco.

Forma: Probablemente rectangular alargada, con faja de enmarque y, quizá, con arco de herradura. 


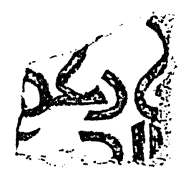

\section{$012345 \mathrm{~cm}$

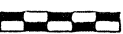

N. ${ }^{\circ} 15$ (Primera mitad del XII).

Medidas: A 6,5 cm x L 6,5 cm x G $4 \mathrm{~cm}$.

Número de líneas: Restos de dos líneas, incompletas.

Tipo de letra: Cúfico de traza simple.

Conservación: Pequeño fragmento que presenta rotura por todas sus partes.

Bibliografía: Inédito.

Texto:

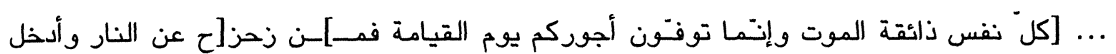

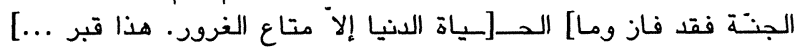

\section{Traducción:}

... [Cada uno gustará la muerte, pero no recibiréis vuestra recompensa íntegra hasta el día de la Resurrección. Habrá triunfado qui]en sea preserva[do del Fuego e introducido en el Jardín]. La vi[da de acá no es más que falaz disfrute (Corán, III, 185). Ésta es la tumba de ...]

\section{Comentario:}

La misma aleya coránica aparece en las inscripciones almerienses $n .^{\circ} 47$ (segunda década del VI), 49 (segunda década del VI), 82 (532/1137) y 118 (5226/1132). También figura en una inscripción valenciana del 345/956 (Barceló, n. ${ }^{\circ}$ 5) y una jiennense del 661/1263 (Lévi-Provençal, n. ${ }^{\circ}$ 158). En todos los casos dicha aleya precede a la identificación del difunto.

Los trazos superiores que aparecen en la segunda línea podrían corresponder tanto a los de la palabra al-ŷanna como a los de al-hayāt, si bien me inclino por esta segunda posibilidad debido a la escasa longitud de la línea en el caso de la primera opción. No ofrezco una posible separación en líneas, pues sería mera conjetura, sin ningún fundamento. 
Fecha: [Primera mitad del siglo XII].

Definición: Inscripción decorativa.

Procedencia: Desconocida.

Ubicación: Museo Provincial de Almería. N. ${ }^{\circ}$ de inventario: 28.801 (frag. a), 28.810 (frag. b) y 28.807 (fragmento c).

Materia: Mármol blanco.

Forma: Rectangular apaisada.

Medidas: A $56 \mathrm{~cm}$ x L $27 \mathrm{~cm} \mathrm{x} \mathrm{G} \mathrm{4,5-6} \mathrm{cm} \mathrm{(frag.} \mathrm{a);} \mathrm{A} 17 \mathrm{~cm}$ x L $23 \mathrm{~cm}$ x G. $4,5-5 \mathrm{~cm}$ (frag. b); y A $29 \mathrm{~cm} \times \mathrm{L} 22,5 \times \mathrm{G} 4,5 \mathrm{~cm}$ (frag. c).

Número de líneas: 1.

Tipo de letra: Cúfico simple.

Conservación: Se trata de tres fragmentos de lo que podría ser un mismo zócalo. La inscripción se ha visto afectada de diferente manera en cada uno de los fragmentos, habiendo resultado el más deteriorado el más grande, que parece haber llegado a perder incluso la banda superior de contarios. El borde superior de las piezas podría ser el original.

Bibliografía: Inédita.

Texto:

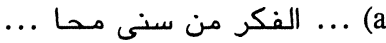

Traducción:

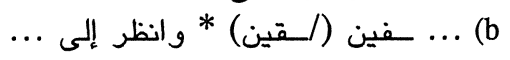

a) ... El pensamiento procede del brillo de ? ...

b) ...? * y mira ...

c) ... ? quien la mira en ...

\section{Comentario:}

Son numerosas las dudas que se presentan en relación con estas piezas. Habiendo descartado que se trate de una fuente o pila, pues el interior no presenta el pulido característico causado por el contacto con el agua, creo que podría tratarse de fragmentos de un zócalo, máxime si tenemos en cuenta la longitud de uno de los fragmentos.

Por otro lado, dada la fragmentación que presenta el texto, no estoy seguro del orden de las piezas.

Parece tratarse de un poema, pudiendo ser el adorno que aparece entre las letras en el tercer fragmento una marca de separación entre hemistiquios o versos.

Uno de los fragmentos, el número 28.807 , presenta restos de policromía de tonalidad verde oscuro. 


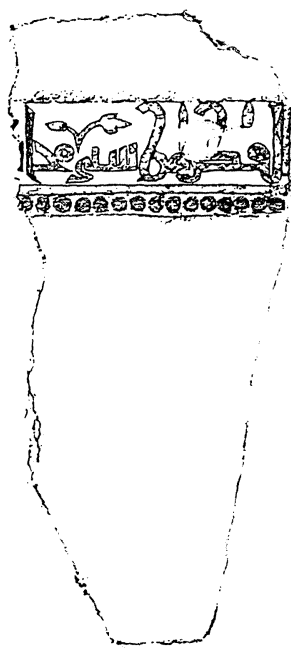

$0123455 \mathrm{~cm}$ $-\infty$

$01234510 \mathrm{~cm}$ $\longrightarrow$

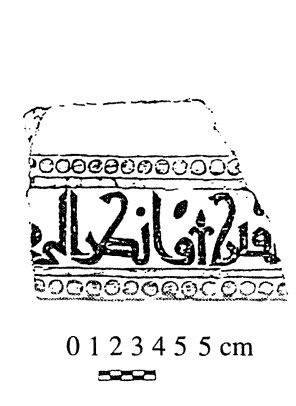

N. ${ }^{\circ} 16$ (Primera mitad del XII). Fragmentos a b y c.

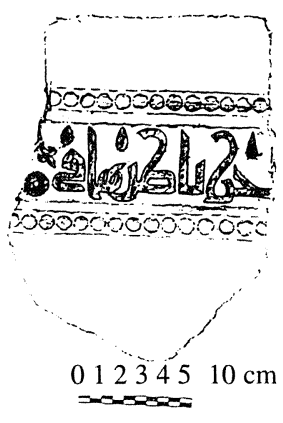

Existen en el Museo otros dos fragmentos (núms. 28.808 y 28.798) que también van enmarcados por bandas de contarios, pudiendo ser uno de ellos el extremo, dado que dichas bandas se cierran por la parte izquierda. Ambos fragmentos presentan decoración anepigráfica y no parecen formar parte del mismo zócalo, pues el mármol en el que fueron labradas presenta características diferentes, aunque este hecho no sea una prueba concluyente. Igual puede decirse del fragmento anepigráfico conservado en el Instituto de Valencia de Don Juan. A todos ellos me referí en relación con la inscripción número 5.

En el Museo también se conserva un bajorrelieve en el que se representan a dos hombres en un sitial de abolengo romano, asociado a otro fragmento con inscripción (sólo aparece la palabra $f i-h i$, «en él»), ambos también con banda de contarios ${ }^{30}$. Tras un análisis comparativo de sus características epigráficas

${ }^{30}$ Según parece, los dos fragmentos fueron descubiertos en la Terraza España, ya inexistente; estaba situada en la actual Avda. de la Estación, a la altura de la calle Altamira. De esta curiosa pieza dieron noticia J. Cuadrado Ruiz (Una visita al Museo Arqueológico, 87 y fotografía en 119 sin 

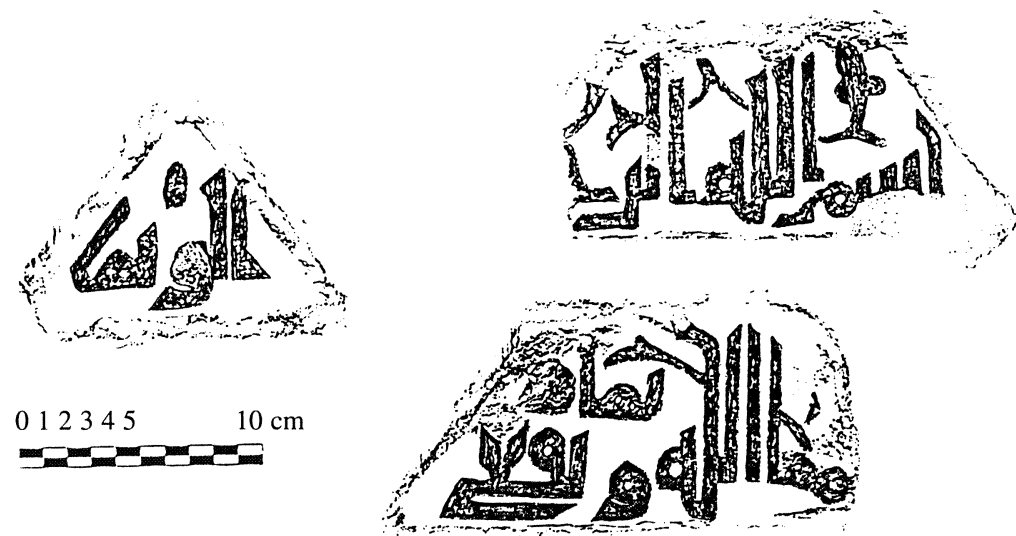

N. ${ }^{\circ} 17$ (Siglo XII). Frentes anterior y posterior y costado derecho.

y otros rasgos, considero que no forma parte de la misma inscripción que aquí presentamos.

Fecha: [Siglo XII].

Definición: Epitafio.

Procedencia: Desconocida. Según consta en la ficha del Museo, fue donado por José Diego Martínez [de Castro] el 13 de octubre de 1955.

Ubicación: Museo Provincial de Almería. N. ${ }^{\circ}$ de inventario: 22.873.

Materia: Mármol blanco.

Forma: Mqābrīya.

Medidas: A 8,5 cm x L 22,5 cm x 16,5 cm.

Número de líneas: 1 por cara.

Tipo de letra: Cúfico simple.

Conservación: Fragmento extremo muy deteriorado. La inscripción aparece sobre un fondo de decoración, aunque no muy tupido.

el fragmento de la inscripción), M. Gómez Moreno (en El arte árabe español hasta los almohades, vol. III del Ars Hispaniae, Madrid, 1951, 274-275, fig. 32, aunque, por error, consigna Gádor como lugar de aparición), L. Torres Balbás (en el vol. V de la Historia de España, dirigida por R. Menéndez Pidal, Madrid, 19824, 713 y fig. 551 en 714) y L. Cara Barrionuevo (La Almería islámica y su alcazaba, 32 y fig. 9 en 33, sin el fragmento con inscripción). 
Bibliografía: Inédita.

Texto:

Frente anterior:

Frente posterior:

$$
1
$$

$$
2
$$

Triángulo del costado derecho:

Traducción:

I En el nombre de Dios, Cle[mente y Misericordioso] ... i ¡Dios se apiade de ella y beneficie, por sus méritos, 1 a sus padres!

\section{Comentario:}

Aunque no se haya conservado la parte en la que se mencionaba el nombre, por la eulogia sabemos que se trata del epitafio de una mujer, que debió de morir en el siglo XII, a tenor de las características epigráficas. La referida eulogia aparece también en otras inscripciones almerienses estudiadas por Ocaña, en concreto la número 57 , que data del 524/1130, y la número 77 , también de la tercera década del siglo vI.

Fecha: [Siglo XII].

Definición: Epitafio.

Procedencia: C. Javier Sanz, en las proximidades del Instituto de Enseñanza Secundaria. Apareció al realizar unas zanjas del alcantarillado.

Ubicación: Museo Provincial de Almería. N. ${ }^{\circ}$ de inventario: 14.743.

Materia: Mármol blanco.

Forma: Mqābrīya.

Medidas: A 9,5 cm x L $28 \mathrm{~cm}$ x G $12 \mathrm{~cm}$.

Número de líneas: 1 por cara.

Tipo de letra: Cúfico simple.

Conservación: Fragmento extremo que presenta algún deterioro en las aristas, pero que no afecta a la inscripción. Ésta aparece acompañada de adornos florales muy integrados en la caligrafía. 


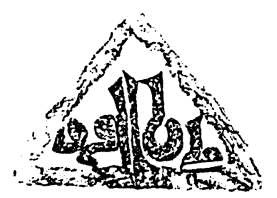

$012345 \mathrm{~cm}$
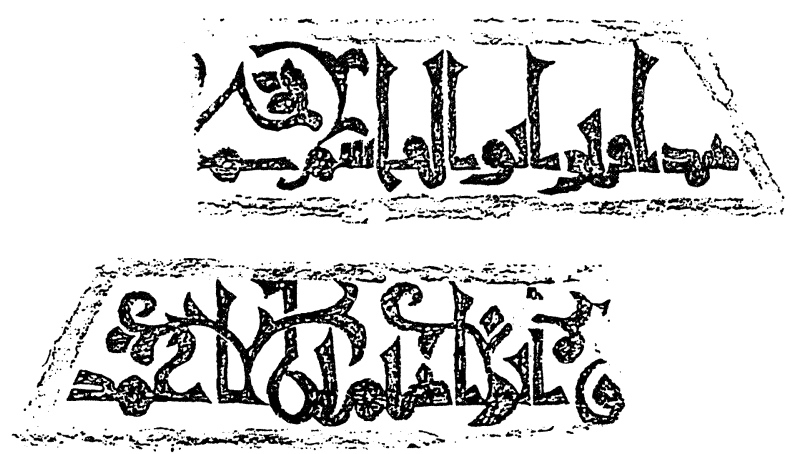

N. ${ }^{\circ} 18$ (Siglo XII). Frentes anterior y posterior y costado derecho.

Bibliografía: Inédita.

Texto:

Frente anterior:

$$
1
$$

Frente posterior:

Triángulo del costado derecho:

$$
2
$$

Traducción:

| Ésta es la sepultura de Abū l-Qāsim M... I I ...q Ibrāhīm b. Aḥmad I ... ?

\section{Comentario:}

Llama la atención que en la mqābrīya tan sólo aparezca el nombre del difunto, en extenso. Ello me hace pensar que la sepultura contaría, probablemente, con otras inscripciones donde aparecerían las habituales fórmulas religiosas y la fecha de defunción.

Seguramente habría que leer en el reverso Ibn Abī Ishạa Ibrāhīm. El hecho de que aparezca la kunya junto al ism de uno de sus antepasados hace pensar que éste habría sido especialmente conocido.

A las letras del triángulo del costado derecho no les encuentro ningún sentido aparente, aunque podría tratarse de un simple nasab mal trazado por la falta de espacio: Ibn al-... 


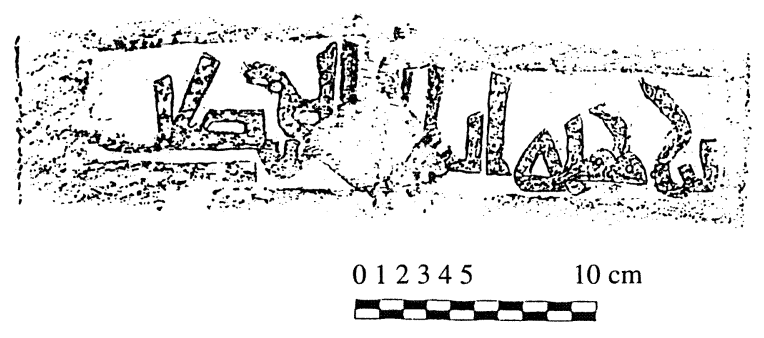

N. ${ }^{\circ} 19$ (¿Siglo XII?).

Fecha: [¿Siglo XII?].

Definición: Epitafio.

Procedencia: Desconocida.

Ubicación: Museo Provincial de Almería. N. ${ }^{\circ}$ de inventario: 82.390.

Materia: Mármol de color rosáceo, de gran porosidad.

Forma: Mqābrīya.

Medidas: A $19 \mathrm{~cm}$ x L $48 \mathrm{~cm}$ x G 21,5 cm.

Número de líneas: 1.

Tipo de letra: Cúfico simple.

Conservación: Fragmento extremo, muy deteriorado, lo que hace que la lectura sea difícil.

Bibliografía: Inédita.

Texto:

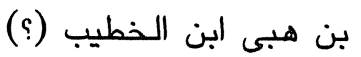

Traducción:

Ibn Hibā Ibn al Jatịib (?)

\section{Comentario:}

La inscripción aparece en un tarjetón transversal que mide unos 26 centímetros de largo por 5-6 centímetros de ancho. Es la misma disposición que presenta la inscripción número 11 de las aquí estudadas.

No estoy seguro de la lectura, dado que ésta presenta numerosos problemas por el mal estado de conservación y el hecho de que fuera realizada sobre un material muy poroso. La segunda palabra parece ser un nombre, pudiéndose 
tratar de Habā/Hibā o Habā'/Habbā'. Para que la lectura de la última palabra sea correcta habría que aceptar que el tallista se equivocó, habiendo suprimido un trazo correspondiente a la $y \bar{a}$ ' o a la $b \bar{a}$ '.

Me resulta muy difícil precisar la cronología a la vista de los escasos rasgos que aparecen, pero creo que puede datar del siglo XII, quizá de su segunda mitad.

\section{RESUMEN}

En este artículo se estudian 25 fragmentos inéditos que forman parte de 19 inscripciones árabes conservadas en el Museo Provincial de Almería. Todas ellas son de Almería, sin que conste el lugar exacto de procedencia, salvo en dos casos. La mayoría, en concreto trece inscripciones, son de carácter funerario; dos son commemorativas o fundacionales; y el resto, cuatro, son decorativas. Su cronología va desde el segundo cuarto del siglo $\mathrm{x}$ al XII, predominando las de época almorávide, que es la época de mayor desarrollo económico de la ciudad.

\section{ABSTRACT}

This paper is a study of twenty-five unpublished fragments pertaining to nineteen Arabic inscriptions, some published previously, preserved in the Provincial Museum of Almería. All are from Almería, although their precise provenance is unknown except in two cases. Most of them, thirteen inscriptions, are funeral; two are commemorative and four are decorative. They date from the second quarter of the tenth century to the twelfth century, though most are from the Almoravid period, a period of intense economic development in Almería. 